\title{
An unusual new genus of istiodactylid pterosaur from China based on a near complete specimen
}

\author{
David W. E. Hone, Adam J. Fitch, Feimin Ma, and Xing Xu
}

\begin{abstract}
A new genus and species of istiodactylid pterosaur, Luchibang xingzhe gen. et sp. nov., from the Lower Cretaceous Yixian Formation of China is erected based on a near complete specimen lacking only the posterior of the skull and the tail. The holotype individual is skeletally immature and already bigger than most istiodactylids suggesting a large wingspan at adult. This is the most complete istiodactylid specimen known to date and provides new information on the anatomy of this group and their putative ecology. The animal is unusual in having postcranial robust and elongate hindlimbs, which marks it as different to other istiodactylids and other pteranodontoids.
\end{abstract}

David W. E. Hone. Queen Mary University of London, Mile End Road, London, E1 4NS, UK.

d.hone@qmul.ac.uk Adam J. Fitch. Department of Geosciences, University of Wisconsin-Madison, 1215 West Dayton St, Madison, Wisconsin 53105, USA. afitch2@wisc.edu

Feimin Ma. School of the Earth Sciences and Resources, China University of Geosciences, 28 Xueyuan Road, Haidian District, 100083 Beijing, China. Ma@sesr.sn

Xing Xu. Institute of Vertebrate Palaeontology and Palaeoanthropology, Xizhimenwai Dajie 142, 100044 Beijing, China.xu.xing@ivpp.ac.cn and CAS Center of Excellence in Life and Paleoenvironment, Beijing, 100044, China.

Key words: Pterosauria; phylogeny; taxonomy; ecology, new genus, new species

Submission: 1 August 2019. Acceptance: 12 February 2020.

\section{INTRODUCTION}

Istiodactylids are a clade of typically mediumsized (2-5 $\mathrm{m}$ in wingspan), pteranodontoid pterosaurs known from Europe, North America and Asia in the Early Cretaceous (Howse et al., 2001; Lü et al., 2008; Witton, 2013). While a number of genera have been described, most specimens are highly incomplete, and large parts of the postcrania are poorly known or unknown. Istiodactylids are characterised by their dentition being constricted to the

http://zoobank.org/B5440D48-7108-4956-B305-A1ECFC7FECD7

Hone, David W. E., Fitch, Adam J., Ma, Feimin, and Xu, Xing. 2020. An unusual new genus of istiodactylid pterosaur from China based on a near complete specimen. Palaeontologia Electronica, 23(1):a09. https://doi.org/10.26879/1015

palaeo-electronica.org/content/2020/2931-a-new-istiodactylid-pterosaur

Copyright: March 2020 Paleontological Society.

This is an open access article distributed under the terms of Attribution-NonCommercial-ShareAlike 4.0 International (CC BY-NC-SA

4.0), which permits users to copy and redistribute the material in any medium or format, provided it is not used for commercial

purposes and the original author and source are credited, with indications if any changes are made.

creativecommons.org/licenses/by-nc-sa/4.0/ 
anterior portion of the skull, the teeth bearing short, triangular roots and the nasoantorbital fenestra (NAOF) being unusually large and occupying most of the skull (Howse et al., 2001).

Here we describe a large and near-complete specimen of a new istiodactylid, Luchibang xingzhe gen. et sp. nov. (Figure 1), which provides new information about the anatomy of the group. Although not the largest known specimen, this represents an animal that is not at skeletal maturity and would potentially have been considerably larger when fully grown. This is also one of the larger vertebrate specimens recovered from the Lower Cretaceous Yixian Formation (though much larger specimens, such as the dinosaur Jinzhousaurus, are known).

Istiodactylid specimens are generally rare, and although the first material assigned to this group was described in the early twentieth century (Howse et al., 2001) less than a dozen specimens are currently known representing eight genera. The phylogenetic position of istiodactylids has changed between various analyses (e.g., Uniwn, 2003; Rodrigues and Kellner, 2013; Vidovic and Martill, 2018) but all of them recover this clade as being within and/or closely allied to the ornithocheirids. Currently valid istiodactylids include Istiodactylus latidens and I. sinensis, Nurhachius ignaciobritoi and N. luei, Liaoxipterus brachyognathus, and Longchengpterus zhaoi, though the validity of the latter had been challenged. However, the Yixian Formation would seem to be a hotspot for their diversity with numerous taxa named and only I. latidens is not from the Early Cretaceous of China. Luchibang is the sixth genus to be described from this formation, and a taxonomic review of key characters suggests that perhaps all of these named istiodactylid taxa are valid.

\section{Geological Setting}

ELDM 1000 was collected in Liutiaogou Village, Dashuangmiao Township, Ningcheng, Neimongol. Due to the private collection of the specimen, little is known about the associated strata of this pterosaur, but it is known to have been collected from within the Lower Cretaceous (Barremian-Albian) Yixian Formation. The Yixian Formation consists of fine-grained lacustrine deposits interbedded with volcanic ash and basalt deposits (Sha, 2007; Chang et al., 2009, 2017). The lacustrine deposits within the Yixian Formation are deposited with great regularity in thickness and composition and display numerous signs of undergoing Milankovitch cycles (see Wu et al., 2013).
The paleontological and paleobotanical record is rich and consists of extremely well-preserved, often complete fossils representing both freshwater and terrestrial (often arboreal or forest specialist) taxa (Ji et al., 2002, Luo et al., 2003, Wang et al., 2006; Wang et al., 2008; Wu et al., 2017). As such, the Yixian formation likely formed within large freshwater lake systems experiencing cyclical, low-flow deposition with frequent and rapidly deposited igneous strata originating from nearby volcanic eruptions (Zhou, 2006).

\section{MATERIALS AND METHODS}

Pterosaur specimen ELDM 1000 from the collections of Erlianhaote Dinosaur Museum (ELDM) was examined first-hand and with a hand lens in this investigation, from which new assignments were made and the phylogenetic relationships of the material were assessed. The specimen was documented using digital photography and vernier calipers.

\section{Repositories and Institutional Abbreviations}

Types, figured, and other specimens examined in this study are deposited in the following institutions: The Natural History Museum (NHM), London, UK; Institute of Vertebrate Palaeontology and Palaeoanthropology (IVPP), Beijing, China; or the Erlianhaote Dinosaur Museum (ELDM), Erlianhote, China.

\section{SYSTEMATIC PALEONTOLOGY}

\author{
PTEROSAURIA Kaup, 1834 \\ PTERODACTYLOIDEA Plieninger, 1901 \\ ISTIODACTYLIDAE Howse et al., 2001 \\ Luchibang, new genus
}

zoobank.org/26BC3ED2-B096-446B-B8D4-35E5E3E99948

Type species. Luchibang xinzhe gen. et sp. nov, by monotypy (please see corrigendum).

Diagnosis. As for the type species.

Occurrence. Liutiaogou Village, Dashuangmiao Township, Ningcheng, Neimongol; the Lower Cretaceous Yixian Formation.

Remarks. Prior to the recognition of Luchibang, Nurhachius was the only istiodactylid known from complete stylopodal and zeugopodal elements from both the fore- and hindlimbs, and these elements are notably longer in Luchibang than in Nurhachius (see Limb proportions of pterodactyloids below). The holotype of Luchibang (ELDM 1000) is also the largest and most complete of known istiodactylid specimens and will provide new information on the anatomy of istiodactylids and the 


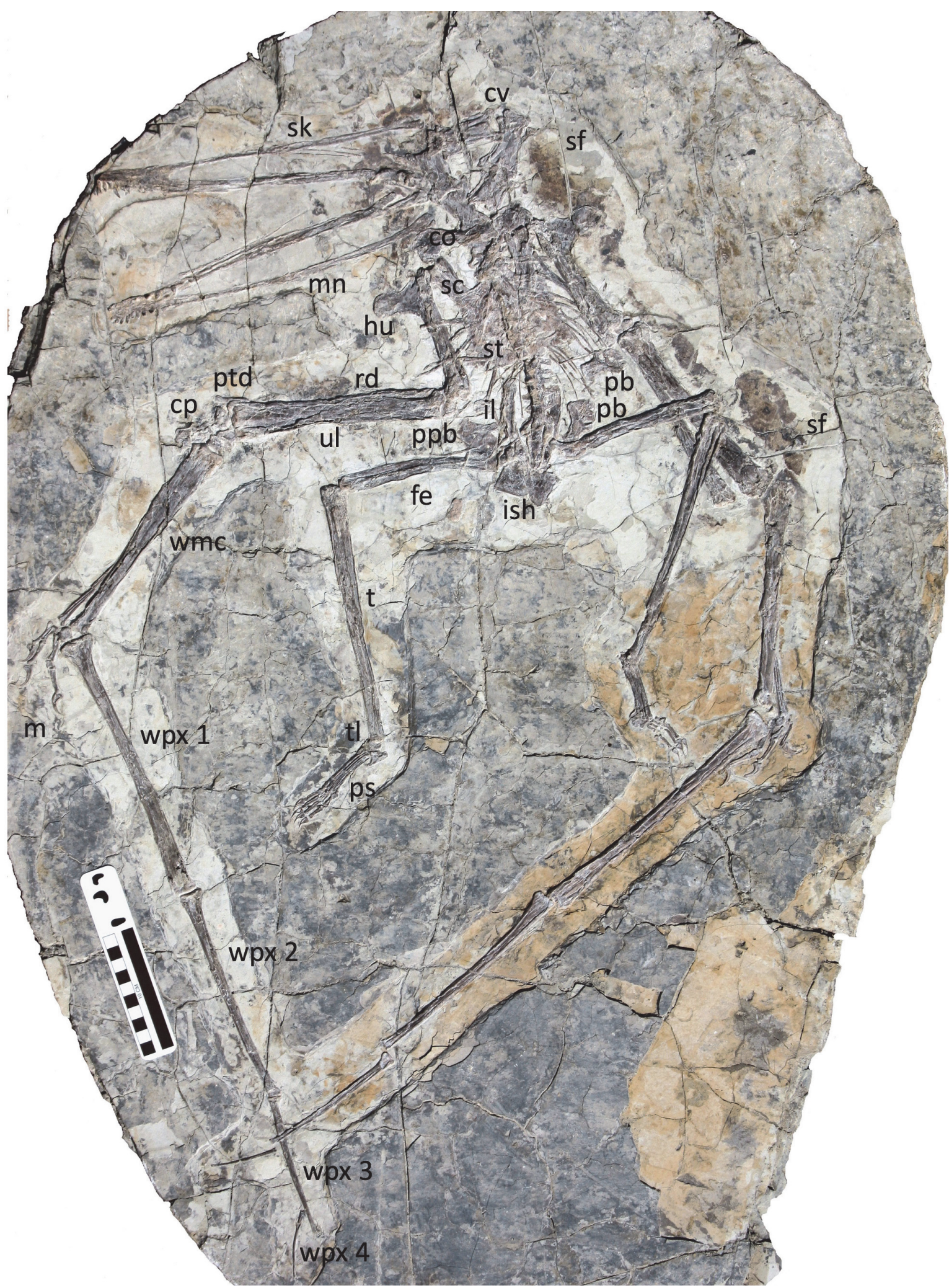

FIGURE 1. Specimen ELDM 1000, holotype of Luichibang xingzhe. Visible scale bar is $100 \mathrm{~mm}$. Abbreviations throughout are as follows: cc, cranial crest; co, coracoid; $c p$, carpals; cv, cervical vertebrae; ep, epiphysis; etp, extensor tendon process; fe, femur; hu, humerus; hy, hyoids; il, ilium; ish, ischium; m, manus; mc, metacarpal; mn, mandible; mt, metatarsal; naof, nasoantorbital fenestra; pb, pubis; ppb, prepubis; ps, pes; ptd, pteroid; r, rib; rd, radius; sc, scapula; sf, soft tissues; sk, skull; st, sternum; t, tibia; tl, tarsals; ul, ulna; wmc, wing metacarpal; wpx, wing phalanx. 
morphological disparity of pterandontoid pterosaurs.

\section{Luchibang xingzhe, new species Figure 1}

zoobank.org/5477C8CD-539D-489E-99CA-FE062045EC00

Holotype. ELDM 1000 (Erlianhaote Dinosaur Museum, Inner Mongolia), a nearly complete articulated skeleton missing only the posterior part of the skull, sternal ribs, the caudal series, one prepubis, and the left carpals and pteroid.

Diagnosis. Istiodactyloid pterosaur that can be distinguished from others in the group by two unique characters: a large, rectangular sternum with a straight posterior edge, and a long femur that is more than $80 \%$ of the length of the ulna. It can be further distinguished from other istiodactylids by the following combination of characters: rostrum with no dorsal expansion anteriorly; very well-spaced teeth in the posterior part of the jaw; a dentary symphysis that is more than four times longer than wide in dorsal view; long and narrow mandibular rami (approximately 20 times longer than wide in dorsal view).

Etymology. Lu to honour our friend the pterosaur researcher Lü Junchang, and from the Mandarin for 'heron' in reference to the fact that this is a long-legged and potentially wading animal, and chibang from the Chinese for 'wing' and xingzhe from the Chinese for 'walker' in reference to the inferred strong terrestrial capabilities of the animal. This should be pronounced as "Loo-chee-bang shing-hey".

Occurrence. Liutiaogou Village, Dashuangmiao Township, Ningcheng, Neimongol; the Lower Cretaceous Yixian Formation.

\section{Description}

The holotype and only known specimen (ELDM 1000) is in excellent condition and represents a near complete and articulated skeleton, preserved with the ventral side uppermost (Figure 1 ). While the specimen is largely compressed into two dimensions, the elements appear to have retained their shape and to have suffered little taphonomic distortion. It is around $2 \mathrm{~m}$ in wingspan (total length of the humeri, ulnae, wing metacarpals, and wing phalanges of both wings).

The specimen is missing the very tip of the snout because the slab is broken. Also absent on the slab are the posterior part of the skull, sternal ribs, the caudal series, one prepubis, and the left carpals and pteroid. The neck is somewhat disarticulated (though all cervicals except the atlas and axis appear to be present), one distal wing phalanx has moved, and the gastralia have been disturbed but all other elements are in natural, or near natural, positions. There may have been a current moving from the animal's right to its left as the displaced elements (e.g., the pelvis) have moved off to the left side and the loose gastralia line up in a left to right orientation.

There are some dark stains and patterns around parts of the bones that appear to be the remnants of soft tissues. There are skin-like features around where the back of the skull would have lain, the left shoulder, left and right ulnae, and the proximal left metacarpals.

Two small fish (probably Lycoptera) are preserved in association with the skeleton. The first lies between the jaws (Figure 2), but the second lies inside the ribs and below the gastralia and may represent gut contents.

The individual was not an adult at the time of death as shown by the lack of fusion in numerous elements across the postcranial skeleton (Bennett, 1995, 1996, Kellner, 2015). The scapula-coracoids are not fused into a single unit, the carpals are unfused, the wing extensor tendon processes are not fused to the proximal wing phalanges, the various elements of the pelvis are unfused, and the tarsals are not fused. There are unfused epiphyses on the distal ends of the humeri, and there may also be an unfused epiphysis on the proximal end of the right ulna. The elements of the wrists and ankles are not only separate, but also rather shapeless and show none of the complexity common to these elements is adult pterodactyloids (e.g., see Kellner and Tomida, 2000). Presumably the skull bones were not well fused as demonstrated by the loss of the posterior part of the skull while the rest of the specimen is undisturbed. Finally, there is some grainy texture to the bones in places, which is generally seen in only very young specimens (Bennett, 1996) although Bennett (2001) describes a 'subadult' Pteranodon with this texture so it may be widely distributed across ontogenetic series. This animal was therefore a juvenile and perhaps a relatively young juvenile. As such, there was probably considerable growth yet to occur, and at adult size this would have been much bigger than that of ELDM 1000.

No pneumatopores can be identified on any element. However, collapsing along the midline of many long bones such as the ulna and metacarpal suggests that they were thin walled with large cavities inside as is normal for pterosaurs (Claessens et al., 2009). Given the pneumatic nature of similar elements in pterodactyloids, it is likely that these 


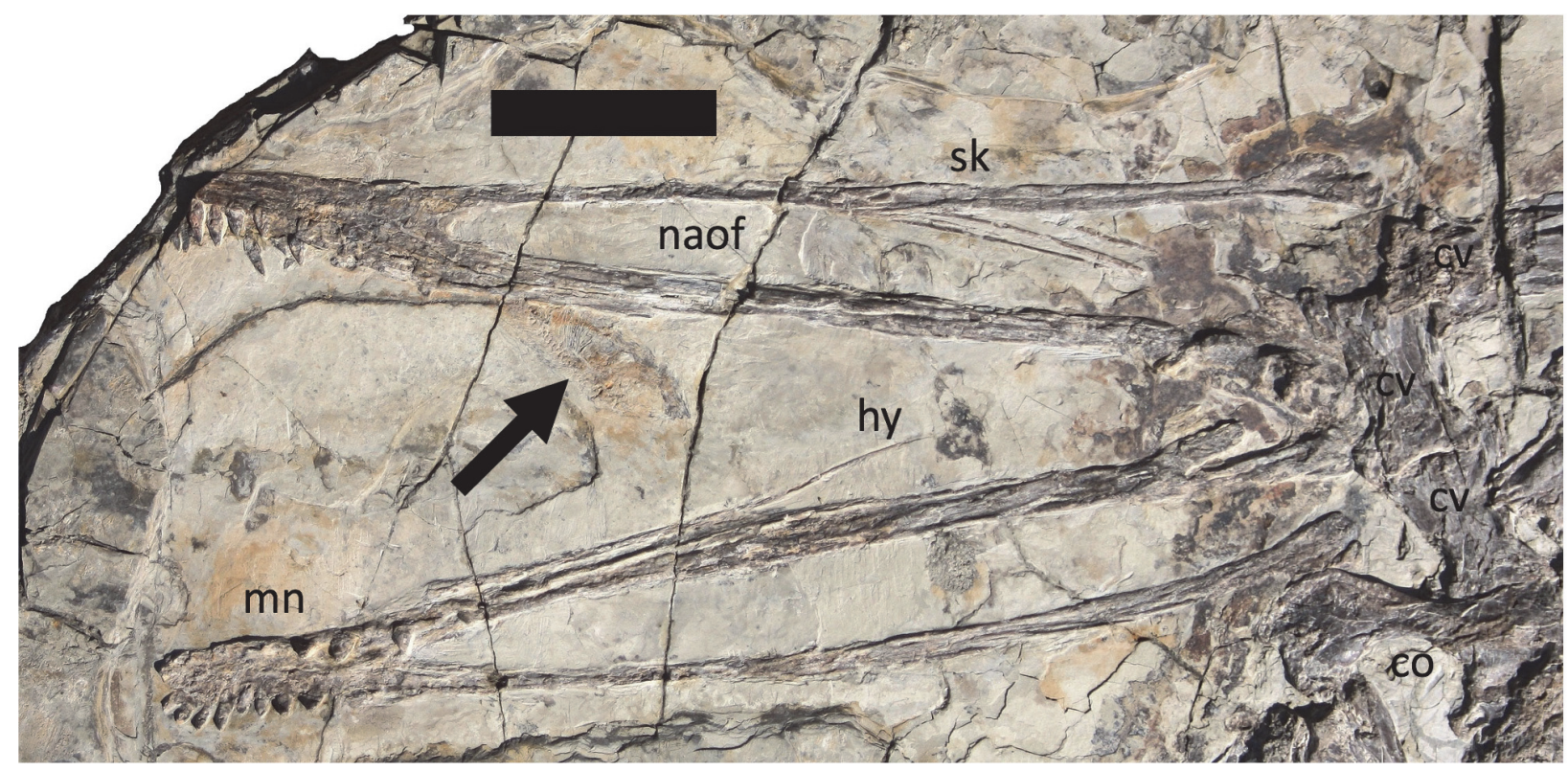

FIGURE 2. Cranium of ELDM 1000. The block arrow points to a fossil fish. Scale bar is $50 \mathrm{~mm}$. Abbreviations throughout are as follows: co, coracoid; cv, cervical vertebrae; hy, hyoids; mn, mandible; naof, nasoantorbital fenestra; sk, skull.

were also pneumatic. As penumaticity increases during ontogeny in birds and at least some other pneumatic ornithodirans (Benson et al., 2012), then there is also a strong possibility that young pterosaurs had lower levels of pneumatic invasions than adults and thus lacked pneumatic openings at this stage that would not reflect the adult condition. Cranium. The cranium as preserved is $268 \mathrm{~mm}$ long, although the very tip of the snout and much of the back of the skull is missing (Figure 2). Thus only the premaxilla and maxilla are preserved and seen in left lateral view. These elements are fused together, and the suture cannot be identified. The left and right sides are slightly misaligned such that the ventral edge of the right side of the premaxillamaxillae is exposed ventral to the left. At the posterior end of the dorsal ramus there is a slight semicircular dorsal enlargement to the bone $(25 \mathrm{~mm}$ long by $6 \mathrm{~mm}$ tall), which may represent part of an incipient cranial crest (Figure 3). No other such posteriorly positioned crests are known in istiodactyloids (though some have a dorsal expansion on the anterior rostrum), though few preserve complete skulls. At the posterior end of the ventral ramus of the maxilla the bone become more robust and expands significantly. The surface of the bone here is rough and likely represents a place for suture with a more posterior part of the skull.

As with all istiodactylids the snout has a gently rounded tip and a large nasoantorbital fenestra
(Arbour and Currie, 2011). The fenestra begins just $57 \mathrm{~mm}$ from the front of the jaw as preserved (about $5 \mathrm{~mm}$ of the rostrum is estimated to be missing) and continues up until the missing posterior part of the skull. Where the preserved skull ends, the NAOF is $36 \mathrm{~mm}$ tall compared to a total height of the skull of just $57 \mathrm{~mm}$. Three long and thin splints of what appear to be bone lie inside the NAOF. They appear to be too thin to be palatal elements, and the hyoids are preserved (see below) so it is not clear what they may represent, though similar invasions stemming from the skull roof are seen in Nurhachius. The missing part of the skull was presumably quite short as in other istiodactylids and would fit with the relative position of the rostrum and the cervical vertebrae. This supports the ideas of a very long NAOF, which is diagnostic for istiodactyloids (Howse et al., 2001). Arbour and Currie (2011) added a useful metric for the anterior extension of the rostrum in istiodactylids: the dorsoventral height of the premaxilla-maxilla at the origin of (and immediately ventral to) the NAOF compared with the length of the rostrum proximal to the NOAF. Luchibang has a ratio here of 0.08 , which is close to that of Nurhachius and I. latidens, though this is about half that of $I$. sinensis.

The mandible is $233 \mathrm{~mm}$ long and appears to be complete. It has rotated along its long axis relative to the skull and is seen in dorsal view. As in other istiodactylids, the anterior edge is rounded 
and presumably the broken upper jaw would have matched this outline (Howse et al., 2011). The symphysis terminates $56 \mathrm{~mm}$ from the anterior part of the jaw and at this point is $20 \mathrm{~mm}$ wide. Each ramus of the jaw is around $12 \mathrm{~mm}$ wide throughout its length. At the posterior end of the jaws the rami expand to form the articular surface with the cranium. On the right ramus a splint of bone has left the main part of the jaw anterior to this expansion. This may represent a separated articular, or damage to the jaw.

The tooth crowns are generally uniform in height and width ( $5 \mathrm{~mm}$ and $3.5 \mathrm{~mm}$, respectively) along the tooth row, though the largest tooth is 6.5 $\mathrm{mm}$ tall and, posteriorly, the teeth have slightly wider bases. They are robust and subcircular in cross-section unlike other istiodacylid teeth, which generally show some labio-lingual compression (Howse et al., 2011; Lü et al., 2008; Wang et al., 2008). Several teeth have moved in their sockets, and the tooth roots are visible. As is characteristic for istiodactylids, the roots are subequal to the crowns in height and triangular in shape (giving the tooth an overall diamond-shaped outline). There is no constriction or expansion at the base of the crown.

The tooth distribution pattern is the same in the rostrum and mandible with the teeth generally being limited to the anterior rostrum only, as in other istiodactylids (e.g., Wang et al., 2006; Andres and $\mathrm{Ji}, 2006$ ). The teeth are closely packed anteriorly, slightly spaced in the middle, and then with large spaces between the last few teeth. In the upper jaw, only six teeth are preserved each side. The way in which they align suggests that there was a minimum of nine teeth in each side of the jaw and probably around 12 in total. The last tooth in the upper row is $58 \mathrm{~mm}$ from the front of the jaw and lying immediately behind the anterior edge of the NAOF. In the mandible there are 12 teeth on each side, and the last tooth lies $72 \mathrm{~mm}$ from the end of the jaw and after the divergence of the rami from the symphysis. While it cannot be tested, based on other istiodactyloids, the teeth would probably tightly interdigitate when the jaws were closed (see Howse et al., 2001).

The hyoids are preserved just above the lower jaw. As with most other pterodactyloids and Liaoxipterus (Dong and Lü, 2005), these have a very long anterior ramus before branching into a pair of posteriorly directed rami. The total length of this element is $143 \mathrm{~mm}$ with the anterior ramus making up the first $77 \mathrm{~mm}$ of this length.
Vertebral column. Six cervical vertebrae are preserved and presumably represent C3-8 (Figure 3) based on their proportions. No istiodactylid specimen is known with a complete neck, but eight cervicals are normal for pterosaurs (Bennett, 1996). The atlas and axis are not visible and were probably lost with the posterior part of the skull, though may be hidden under other cervicals. C8 is partially covered by the scapulocoracoid and cannot be observed easily, but does articulate with the dorsal series and is therefore the last cervical. The neck is somewhat disarticulated with the individual vertebra at strong angles to one another (especially the series 4-6 in Figure 3). Seen in ventral view, it cannot be determined if the neural arches are separate from the centra as might be expected for a young animal.

The cervical vertebrae are elongate, though C3 and C8 are shorter with the middle cervicals being the longest. The middle centra are twice as long as wide (around 40 by $21 \mathrm{~mm}$ ). The centra are narrow-waisted and expand proximally and distally, and have a slightly dished face anterior and posteriorly but are not greatly elongate. In general proportion they are similar to those of the pteranodontoids (sensu Keller, 2003 - the istiodactylids, ornithocheirids, and pteranodontids) such as Hongshanopterus (Wang et al., 2008) Moganopterus (Lü et al., 2012) and Anhanguera (Kellner and Tomida, 2000) and the azhdarchoid Jidapterus (Dong et al., 2003).

There is a conspicuous bulge in the bone at the anterior end of the ventral face of each vertebra. Each vertebra has large pre- and postzygapophyses and small postexapophyses. The prezygapophyses expand laterally and terminate well short of the anterior end of the centrum. In contrast, the postzygapophyses extend posteriorly well beyond the posterior face of the centrum. This differs in the holotype of Nurhachius (Wang et al., 2005) where the pre- and postzygapophyses are subequal in length.

The first dorsal vertebra is exposed, but the other proximal dorsals are hidden beneath the sternum and cannot be observed. The sternum is thin, however, and the shapes of the dorsals can be partly made out underneath suggesting that seven are hidden below this bone. Posteriorly to the sternum, a further five dorsals are exposed for a total of 13 dorsals. These are very similar to D1 suggesting a uniform morphology for the whole dorsal series. Each has a centrum around $10 \mathrm{~mm}$ in length and width. The posterior dorsals are distinguished from the sacrals by having differently 


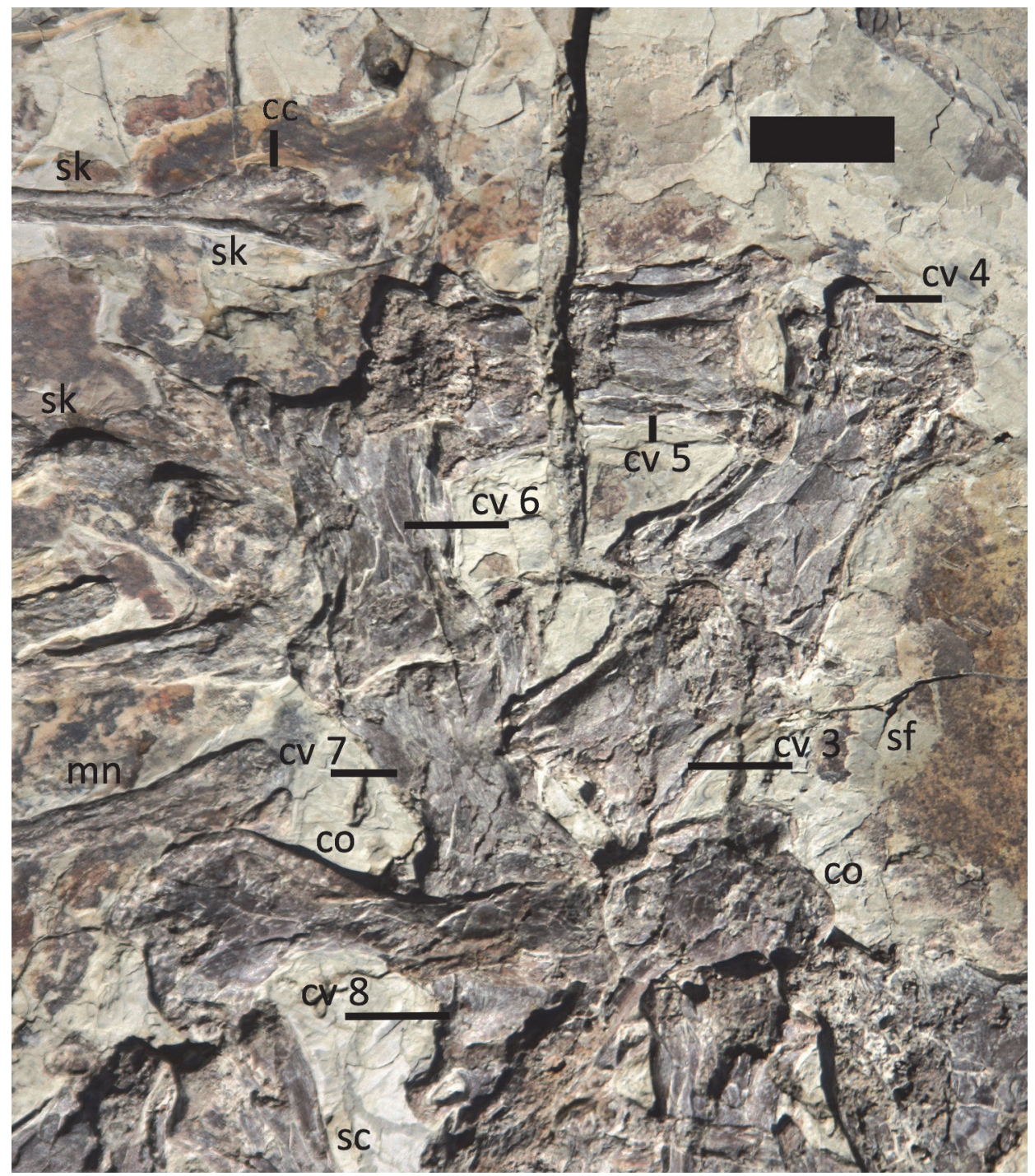

FIGURE 3. Cervical column of ELDM 1000. Cervicals are numbered. Scale bar is $50 \mathrm{~mm}$. Abbreviations throughout are as follows: cc, cranial crest; co, coracoid; cv, cervical vertebrae; mn, mandible; sc, scapula; sf, soft tissues; sk, skull.

shaped lateral processes to the sacrum (though some of all of these could potentially be incorporated into the synsacral block later in ontogeny).

There are at least seven ribs preserved on each side of the body (Figure 4). However, the rib heads and proximal shafts are covered by the sternum, and some of these have separated and moved somewhat from their natural articulations and are mixed with the gastralia, making exact identifications difficult. The proximal ribs are about $5 \mathrm{~mm}$ in diameter in the midshaft region with more posterior ribs being slightly narrower. Some gastralia can be identified lying around the pelvis, particularly around the right hand side. These gastralia are around $40 \mathrm{~mm}$ long and thin, with a slight curvature along their length.
Five sacrals are visible, though more may be present distally under the ischia. The centra of the visible sacrals are fused into a solid block, which is $45 \mathrm{~mm}$ long. These have long and relatively narrow sacral ribs that are subequal in length to the width of the centra. These are not fused to the ilia, which have separated.

The tail cannot be seen. It may be hidden below the ischia, but this is considered unlikely and is presumed lost. There are two very small bony elements lying posterior to the left ischium and these could represent the distalmost caudals. If so, then the tail is very short compared even to other pterodactyloids (Hone and Lü, 2010).

Limb girdles. All measurements given hereafter refer to the maximal length of an element and the 


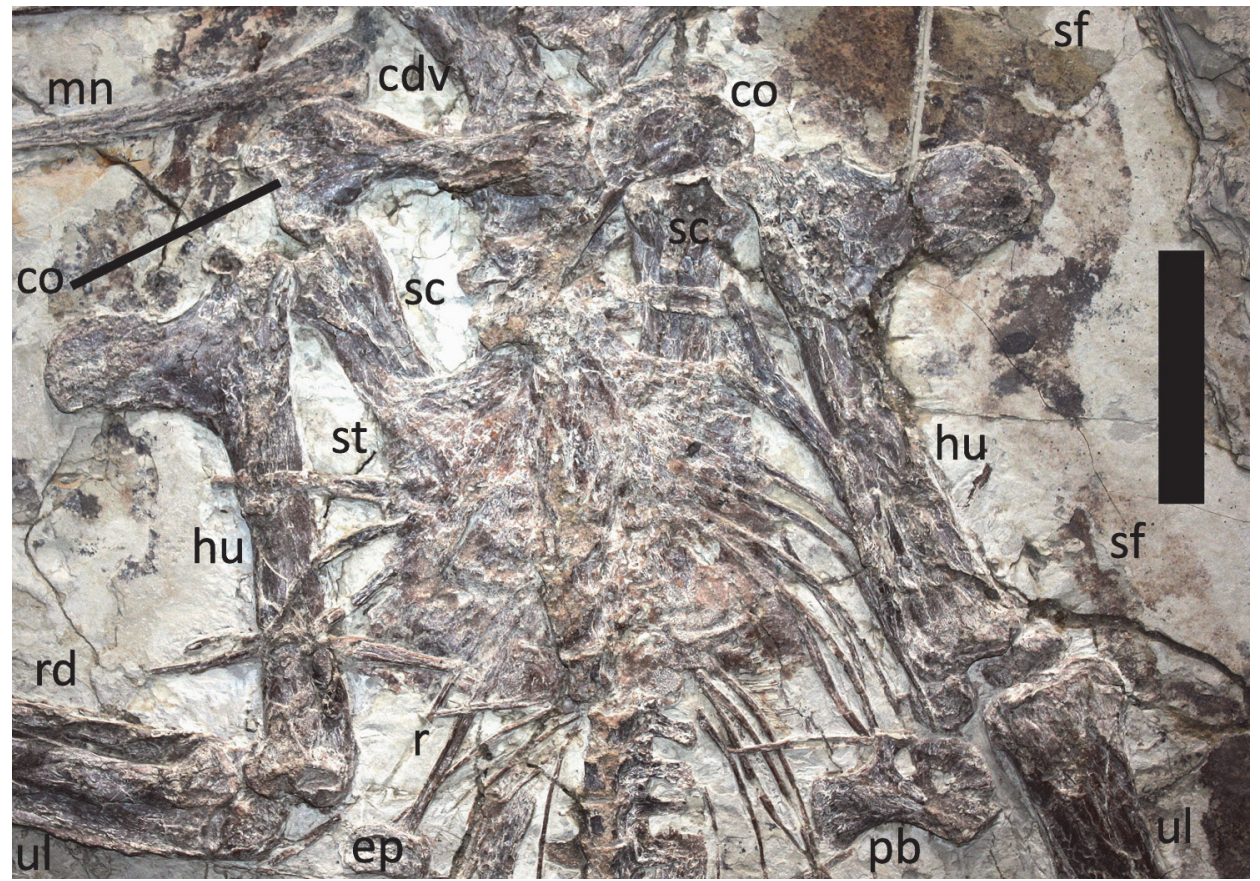

FIGURE 4. Chest region of ELDM 1000. Scale bar is $50 \mathrm{~mm}$. Abbreviations throughout are as follows: cdv, cervicodorsal vertebrae; co, coracoid; ep, epiphysis; hu, humerus; mn, mandible; pb, pubis; r, rib; rd, radius; sc, scapula; sf, soft tissues; st, sternum; ul, ulna.

width taken at the midpoint / midshaft of the bone unless otherwise stated. The length is given first, then the midshaft width. Each is rounded to the nearest whole $\mathrm{mm}$.

The scapulae are largely hidden by the sternum and ribs and cannot be easily observed or measured (Figure 4), though the margins of the bones underneath the sternum are visible, and this allows an estimate of their length to be taken. The scapulae are here considered to be slightly shorter than the coracoids, or subequal in length to them as seen in Nurhachius (Wang et al., 2005) where these are also unfused and also in the osteologically mature $\mathrm{I}$. sinensis (Andres and $\mathrm{Ji}, 2006$ ). The scapulae are straight and robust as is normal for istiodactylids (Witton, 2013) and lie subparallel to the dorsal series. Proximally they are about $23 \mathrm{~mm}$ in width. These are articulated with, but not fused to, the coracoids. Both the scapulae and coracoids have unusually expanded ends not seen in other pterosaurs, and these are also rounded as seen in Nurhachius (Wang et al., 2005).

Both coracoids are present, though the left is rather less well preserved than the right (Figure 4). Each is around $70 \mathrm{~mm}$ long and $9 \mathrm{~mm}$ wide, though the proximal and distal ends are both enlarged considerably (16 and $30 \mathrm{~mm}$ wide, respectively) and gently rounded. The lack of fusion between the scapulae and coracoids and their respective orientations means that nothing of the shape and size of the glenoid can be determined.

The sternum is very large and subrectangular in shape (Figures 1,4) measuring 85 by $70 \mathrm{~mm}$. There is a slight expansion along the anterior edge that may be part of a cristospine, but no anterior and ventral projection as in many other pterosaurs, though this may have been lost or was unossified. However, this is similarly lacking in the holotype of Nurachius and thus may be genuinely reduced or absent in some istiodactylids. The lateral edges of the sternum are serrated (presumably marking articulation points for the sternal ribs), while the posterior edge is straight. With the exception of the cristospine, this bears a striking similarity to the sternum of the pteranodontid Pteranodon (Bennett, 2001) and is generally similar to other pterodactyloids (Lü et al., 2011). However, the straight anterior and posterior edges are rather different to other istiodactylids (Howse et al., 2001; Wang et al., 2005) although similar to the istiodactyliform Mimodactylus (Kellner et al., 2019).

The pelvic elements are disarticulated and are overlapping in places (Figure 5). A single large prepubis is present (probably the right) and lies just anterior to the proximal right femur and lateral to the right ilium. The prepubis is subrectangular in shape and is $36 \mathrm{~mm}$ long and $18 \mathrm{~mm}$ wide. A 10 


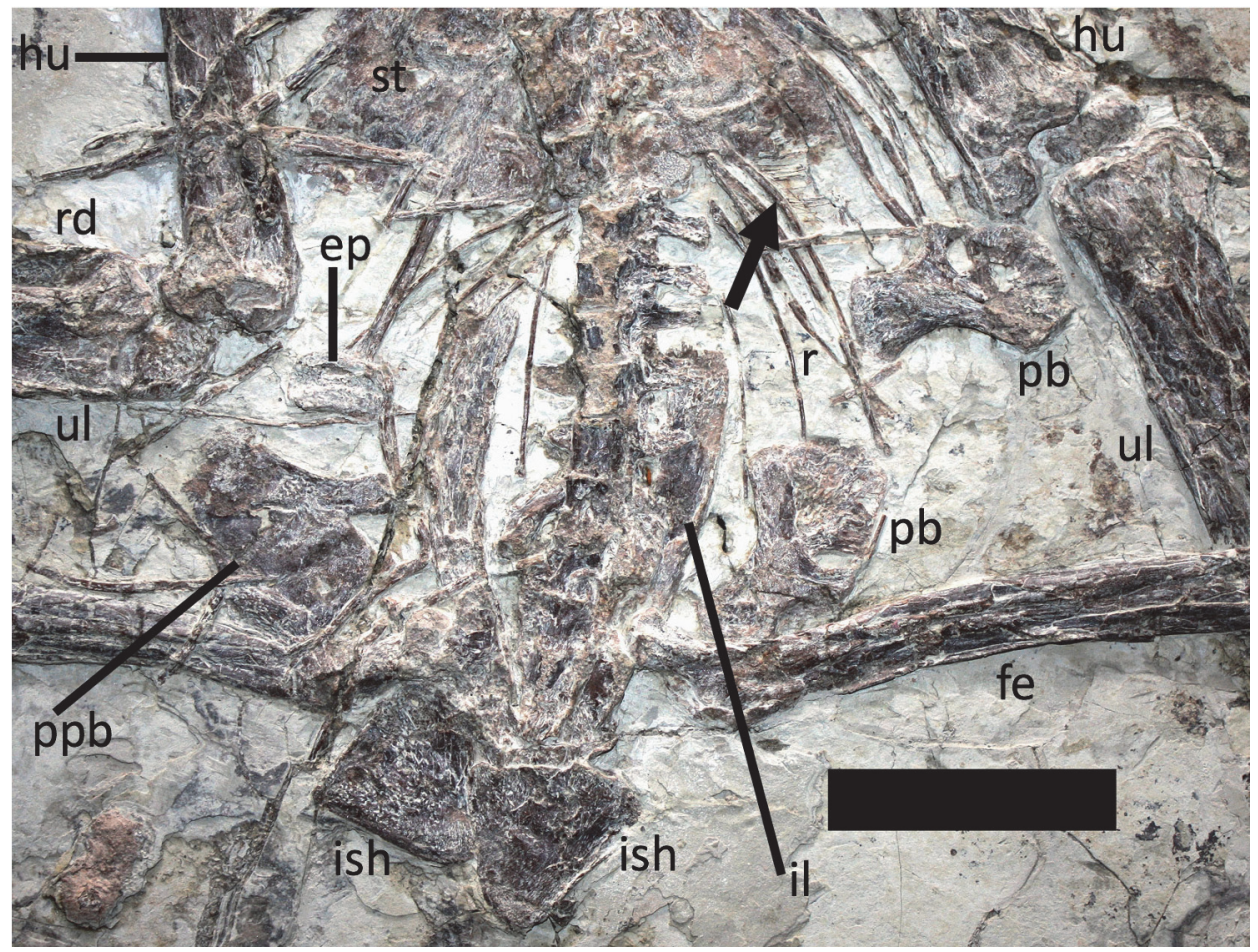

FIGURE 5. Pelvic region of ELDM 1000. Scale bar is $50 \mathrm{~mm}$. The black arrow points to a fossil fish largely concealed by a rib. Abbreviations throughout are as follows: ep, epiphysis; fe, femur; hu, humerus; il, ilium; ish, ischium; pb, pubis; ppb, prepubis; r, rib; rd, radius; sk, st, sternum; ul, ulna.

$\mathrm{mm}$ long projection extends of the anterior edge and would articulate with the pubis.

The ilia are seen in medial view and form a long pair of anteriorly directed rami that run subparallel to the vertebral column, with the posterior parts being hidden by the ischia. The anterior rami are short as with other pteranodontoids and different to the elongation seen in ctenochasmatids and late branching neoazhdarchids (Hyder et al., 2014). There is a slight degree of curvature along the rami, and the anterior ends are well rounded. The ilia are at least $65 \mathrm{~mm}$ long and the rami 10 $\mathrm{mm}$ wide. The acetabulum is partly covered by the femoral head but can be seen to be $13 \mathrm{~mm}$ across the dorsal extent. The rest of the acetabular shape or size cannot be determined owing to the disarticulation of the pubes and ischia.

Both pubes are present but have moved. The left lies close to its natural articulation point, but the right has moved further and lies next to the left elbow. Each pubis is subtriangular with a large and robust projection directed proximally to connect to the ilia, which differs from the condition seen in ctenochasmatids where this is often rectangular (Hyder et al., 2014). The main plate of each pubis is thinner than the projecting part of the pubis and is penetrated by a small oval foramen $(5 \mathrm{~mm}$ by 2 $\mathrm{mm}$ wide) close to the posterior edge of the plate. The exact orientation of the ischia is hard to determine as they are disarticulated and are partly overlapping, though they appear to be preserved in lateral view. They are subtriangular in shape with rounded corners and with each edge being around $27 \mathrm{~mm}$ long.

Limbs. All four limbs are well preserved, though the long bones have suffered some crushing, and there is a slight disarticulation of the bones at most joints (Figure 1). Measurements and descriptions are based on the right side, though there are slight differences between the lengths of various bones between the left and right. All elements unless otherwise stated are seen in medial view.

The humerus is $110 \mathrm{~mm}$ long, and the shaft is $15 \mathrm{~mm}$ wide (Figure 1). The proximal end appears rounded and is straight distally. There is a pair of unfused epiphyses associated with the distal end of each humerus. These consist of one short and square epiphysis and a longer subrectangular one. On the right hand side, the longer piece has moved and lies close to the right prepubis. The deltopectoral crest is long and extends $36 \mathrm{~mm}$ from the shaft and $18 \mathrm{~mm}$ tall at the midpoint. The distal end of the crest is also rounded and there is a constriction in the middle of the crest is broadly similar to 


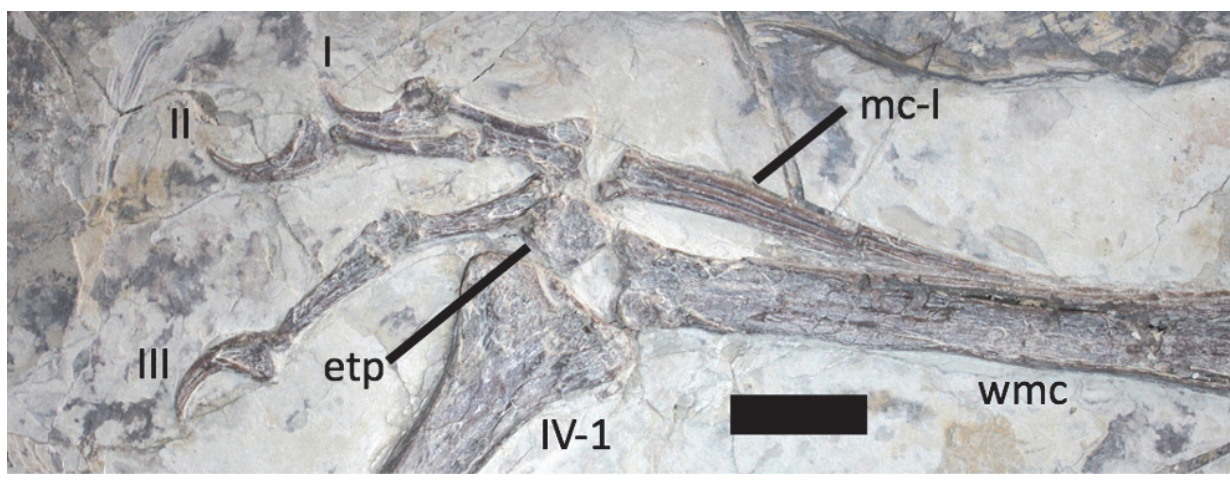

FIGURE 6. Manus of ELDM 1000. Abbreviations throughout are as follows: etp, extensor tendon process; mc-I, metacarpal I; wmc, wing metacarpal; I, digit I; II, digit II; III, digit III; IV-1, wing phalanx I. Scale bar is $20 \mathrm{~mm}$.

that of Nurhachius. One deltopectoral crest appears to be rather longer than the other. We attribute this to the possession of a warped crest (as is normal for istiodactylids - Witton, 2012) but whereby here one of the two humeri has been crushed such that the crest has flattened out and thus appears to be longer. A kidney-shaped piece of bone lying close to the right ilium is considered an epiphysis that has separated from the distal humerus (Figure 5).

The right radius is hidden below the ulna but on the left, the radius and ulna have separated so that both are clearly visible. Both are simple and straight elements with slightly enlarged proximal and distal ends. Proximally the ulna has a twin condyle, but distally the articular surface is flat. Unlike other istiodactylids (e.g., I. latidens), the radius is not significantly reduced in diameter (the ulna is 1.2 times the diameter of the radius), though it does increase slight along its length such that the distal end is broader than the proximal. The ulna is $173 \mathrm{~mm}$ long and $14 \mathrm{~mm}$ wide and is 1.6 times the length of the humerus.

Approximately five elements are preserved in the right wrist. These are each subrectangular in outline and around $10 \mathrm{~mm}$ across. These are disarticulated and not well preserved so their exact identities are difficult to determine, but presumably the wrists are fundamentally complete. Only the right pteroid is preserved and this is partly covered. As seen, it is $29 \mathrm{~mm}$ long and $4 \mathrm{~mm}$ in diameter. It is a simple straight element. The left wrist bones and pteroid are missing (Figure 6).

The wing metacarpal (MC 4) has a broad proximal articulation $(29 \mathrm{~mm})$ with the wrist but tapers strongly along its length (to $15 \mathrm{~mm}$ distally) with a slight distal expansion at the condyle for articulation with the first wing phalanx. MC 4 is 182 $\mathrm{mm}$ long and so slightly longer than the ulna. The wing metacarpal is only slightly longer than the radius/ulna, which is unusual for an istiodactylid where the metacarpal is shorter in Istiodactylus sinensis (Andres and Ji, 2006) and Nurhachius (Wang et al., 2005).

Metacarpals 1-3 appear only distally on the wing but it is not clear if their proximal ends are hidden below the wing metacarpal, or if these are genuinely short and appear only distally (as seen in a number of late branching pterodactyloids). They are fused at their base suggesting that they are genuinely short and that their full length (or close to it) is visible (Figure 6). As seen these are subequal in length at around $65 \mathrm{~mm}$ and $3 \mathrm{~mm}$ in diameter and with slightly expanded and subcircular distal articular ends.

The hand has the typically pterosaurian formula of 2-3-4-4-X. Of the three fingers of the manus (i.e., not including the wing finger) the first is the shortest and the third the longest (Figure 6). The phalanges are thin but with strongly expanded proximal ends and slight expansion distally. Several are ventrally curved, most notably phalanx 2.1 and 2.2. The claws are quite long $(18 \mathrm{~mm}$ measured in a straight line from base to tip) and strongly recurved and terminate at a sharp tip. Each ungual has a deep and well-rounded flexor tubercle. Along the midline of the lateral face of the unguals are deep grooves (Figure 6). These lie in contrast to the rather shallow grooves, and tips that are curved back towards the manus as seen in Nurachius (Wang et al., 2005).

The wing phalanges and in ventral view and reduce strongly successively (Figure 1) such that they make up $39 \%, 31 \%, 21 \%$, and $9 \%$, respectively, of the wing finger (these are 219, 174, 115, and $55 \mathrm{~mm}$ ). Longchengpterus has no wing phalanx four preserved, however, phalanges 1-3 here are in the ratio of approximately 4:3:2 in length 


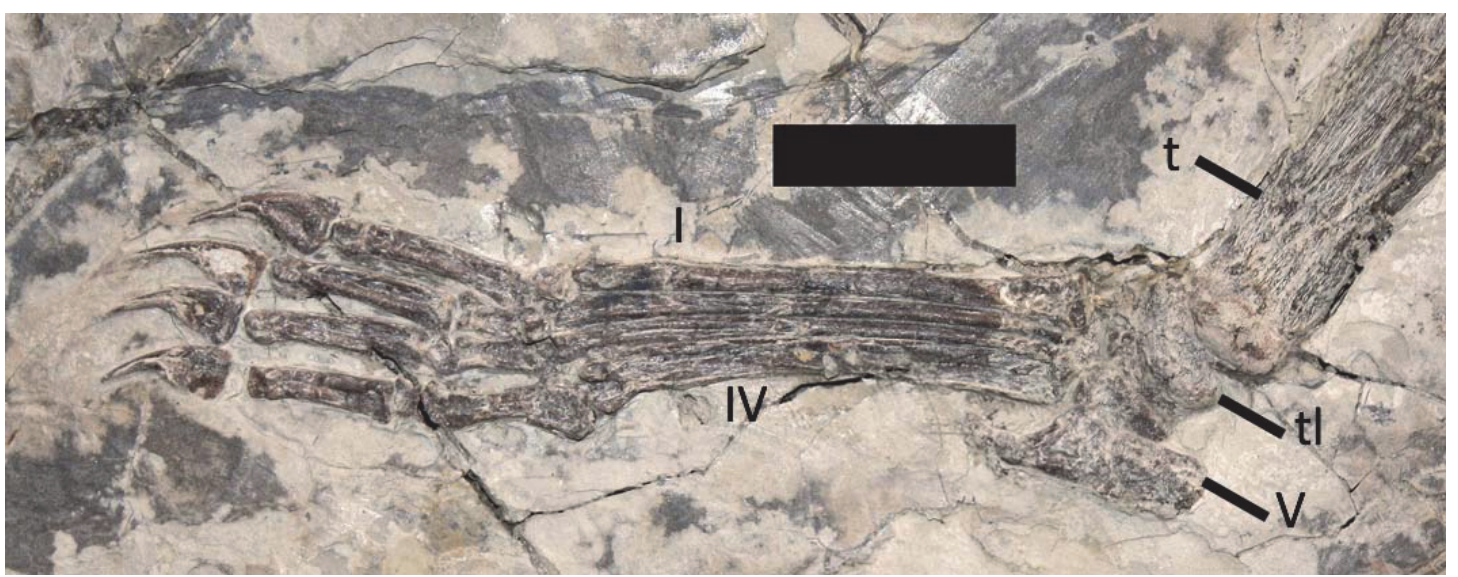

FIGURE 7. Pes of ELDM 1000. Abbreviations throughout are as follows: t, tibia; tl, tarsals; I, metatarsal I; IV, metatarsal IV; V, metatarsal V. Scale bar is $20 \mathrm{~mm}$.

(Wang et al., 2006) and thus are similar to that seen here in Luchibang. This ratio is also seen more widely and appears in azhdarchoids such as Jidapterus (Dong et al., 2003) as well as these two istiodactylids. In total, the wing finger makes up slightly more than $50 \%$ of the total length of the wing, which has been predicted for istiodactylids (Witton, 2013).

The extensor tendon process has not fused to the proximal phalanx of either wing finger and is preserved separately as a square of bone $12 \mathrm{~mm}$ along each side. The phalanges are typical of pterodactyloid wings with slight posterior expansions at each knuckle. The last phalanx on each wing has a slight posteriorly directed curvature.

The left femur is better exposed and shows that the femoral head is only slightly offset from the shaft (Figure 5) as is normal for pteranodontoids and other istiodactylids (Witton, 2013). The femur is long at $143 \mathrm{~mm}$ (1.3 times the length of the humerus, and 0.84 times the length of the ulna), is slightly curved along its length, and $13 \mathrm{~mm}$ wide. There is a long neck for the head, which at $7 \mathrm{~mm}$, is significantly less robust than the femoral shaft. The femoral head is ball shaped and expanded relative to the neck. The neck is only slightly offset from the shaft (i.e., the head is almost in line with the shaft), and there is a clear 'shoulder' to the lateral femur where the neck leaves the shaft. The shaft expands along its length and is broader distally then proximally. The distal condyle is simple and slightly expanded compared to the femoral shaft.

The tibia is $212 \mathrm{~mm}$ long and $10 \mathrm{~mm}$ wide and is 1.5 times the length of the femur, which is considerably longer than may be expected as the tibia is subequal to the femur in Nurhachius (Wang,
2005). This is a simple element with straight proximal and distal ends. The proximal end is broader than the distal such that there is a gentle but continuous tapering along the length of the bone. Only the left fibula is visible, and this is exposed at the proximal end of the tibia. It is $61 \mathrm{~mm}$ long, though more may be hidden behind the tibia. It is only 4 $\mathrm{mm}$ across proximally and so is strongly reduced relative to the tibia and is only a small element. Although fused to the tibia proximally and distally, most of the anterior portion of the fibula is free of the tibia.

The right foot is in good condition (Figure 7), but the left is less well preserved. On both sides a number of tarsals are visible, though as with the wrists, exact identifications of individual elements are not possible. Metatarsals I-IV are long (around $45 \mathrm{~mm}$ long) and narrow ( $3 \mathrm{~mm}$ wide). This apparent narrow width may be misleading as in the left foot, metatarsal IV seems to have rotated slightly and is nearly twice the width of I-III. Metatarsals I and II are the longest with IV being the shortest, each is flat proximally with a slight condyle seen distally. Metatarsal 5 is $18 \mathrm{~mm}$ long and is unusually robust (6 $\mathrm{mm}$ wide) with a proximal expansion.

The phalanges of the foot are slightly disarticulated and overlap in places. As with the metacarpals, each element is around $3 \mathrm{~mm}$ in diameter. The elements of digits I-IV are largely long and straight. Phalanx 1 of digit is just $4 \mathrm{~mm}$ long. There is a simple and slight ginglymoid articulation on the distal end of the penultimate phalanges of digits IIV. The unguals are proximally tall but constrict rapidly in height such that their distal two-thirds are very thin and needle-like with a slight curvature (Figure 7). There is a lateral groove that proximally begins closer to the dorsal edge of the ungual than 
the ventral, but after tapering occurs, this runs down the midline of the claw midline to the tip.

Soft tissues. Several patches of soft tissues are preserved in association with the specimen (Figures $1,3,4)$. There is one at the back of the skull/ neck, on the left shoulder, and associated with both ulnae. These patches are brown to black stains of tissue that is stippled in a manner similar to other skin and soft tissue impressions for other pterosaurs (e.g., Hone and Lü, 2010; Kellner et al., 2009; Sullivan et al., 2014). This consists of a fine patina that looks like it could be composed of very fine scales or even smooth skin (Figure 3). Unfortunately, it has not yet been possible to examine the material under a microscope to examine fine details of this.

\section{Remarks}

Luchibang is supported as an istiodactylid pterosaur based on the following two characters of Andres and Ji (2006) "[p]terodactyloids with nasoantorbital fenestra constituting over 58 percent of skull length and height, and labiolingually compressed lancet-shaped teeth with truncated triangular roots." Witton (2012) also listed traits that support the istiodactylids as a clade seen here extension of the nasoantorbital fenestra posterior to the jaw joint; a broad, rounded jaw tip in dorsal or ventral aspect; pre-narial rostrum less than 30 percent of the jaw length" (although in Nurhachius the NAOF terminates above the jaw joint). As noted above, the size of the NAOF of Luchibang is only inferred here based on the reasonable assumption that the back of the skull would be a relatively small component of the material, an inference supported by the position of the anterior cervical vertebrae on the slab. Examination of other istiodactylid specimens suggests that additional characters can be added to this diagnosis for the clade: teeth closely appressed in the anterior end of the jaws (also seen in the ctenochasmatid Pterodaustro), only gentle tapering of the skull rostrally to terminate in a semi-circular anterior end.

Istiodactylid taxonomy is problematic as a number of important taxa are known from, and their diagnoses are based on, only very highly fragmentary remains of anterior skulls and mandibles. Further important characters are provided by the posterior part of the skull (especially for species of Istiodactylus - Andres and $\mathrm{Ji}, 2006$ ) though this is absent here. Thus while Luchibang does provide extensive new information about the anatomy of this group, determining its generic and specific identity is difficult. Nevertheless, Luchibang can be separated from most other istiodactylids by a series of cranial characters.

The Chinese istiodactylid Longchengpterus (see Wang et al., 2006; Lü et al., 2008) is similar in size to Luchibang, though this is an adult specimen, and thus the latter is likely much larger when fully grown. Longchengpterus has a long rostrum anterior to the NAOF not seen in Luchibang, and the symphasis of the dentary is about a third of the length of the lower jaw as opposed to one-fifth of the length seen here. The anterior rostrum of Longchengpterus also seems to be dorsally expanded (in a manner of many ornithocheirids and some other istiodactylids) which is not seen in Luchibang. There are only nine teeth on each side of the lower jaw and in the mandible all of the teeth lie anterior to the posterior end of the symphasis (Lü et al., 2006) which is not seen in Luchibang. The teeth of Longchengpterus are far more strongly laterally compressed (Wang et al., 2006) than the near conical teeth of Luchibang.

The validity of Longchengpterus has been questioned as Lü et al. (2008) synonymised this with Nurhachius, and this has been supported (Kellner et al., 2019) and rejected (Witton, 2012) by various authors. Both are provisionally considered valid here. N. ignaciobritoi is clearly separated from the latter by having 14 and 13 teeth in the upper and lower jaws, respectively, as opposed to 9 in each, and a proportionally small skull (2.6 times the length of the humerus, compared to 3.3 times in Longchengpterus). As neither taxon has been described in detail further differences may well be apparent on further inspection - at the very least we suggest this may represent a different species.

Luchibang is clearly different to $N$. ignaciobritoi as it lacks a dorsal expansion of the rostrum present in the latter taxon and the long rostrum anterior to the NAOF of $N$. ignaciobritoi. Luchibang also lacks constrictions at the base of some of the teeth and these are more robust than the laterally compressed teeth in $N$. ignaciobritoi (IVPP V 13288). Luchibang also has a large sternum with a straight posterior and lateral edges, as opposed to a posteriorly rounded sternum that is much smaller and fan-shaped in N. ignaciobritoi. The very recently described Nurhachius luei is a second species of this genus, and is represented by a skull and cervical vertebrae (Zhao et al., 2019). This has numerous cranial features in common with $N$. ignaciobritoi and as such is clearly separate from Luchibang (see Table 1). Compared to the new genus here, $N$. luei has a long and upturned ros- 
TABLE 1. Key cranial characteristics of a variety of istiodactylids. A ' 0 ' indicates a character is absent, ' 1 ' is present, and '-" is unknown. *The anterior tip of the jaw is missing and this is estimated for this calculation. **The tip of the jaw is missing and more teeth were likely present, probably 12 in total. "I. latidens has 25 teeth in the lower jaw with a tooth positioned medially at the front. Information taken from Howse et al., 2001; Andres and Ji, 2006; Wang et al., 2005, 2011; Lü et al., 2008; Arbour and Currie, 2011; Zhou et al., 2019 and examination of BMNH R8377 (referred specimen of $I$. latidens) and IVPP V 13288 (holotype of Nurhachius ignaciobritoi).

\begin{tabular}{|c|c|c|c|c|c|c|c|c|}
\hline & 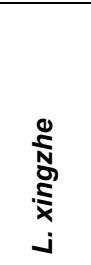 & 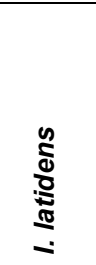 & $\begin{array}{l}\frac{n}{5} \\
\frac{5}{\Phi} \\
\stackrel{5}{5} \\
-\end{array}$ & 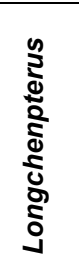 & 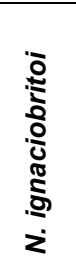 & 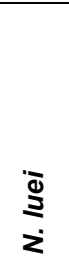 & 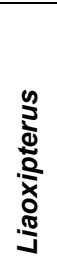 & 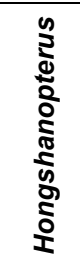 \\
\hline Dorsal expansion / upturn of anterior rostrum & 0 & 0 & 1 & 1 & 1 & 1 & - & - \\
\hline Length-height ratio of rostrum anterior and ventral to NAOF & $0.11^{*}$ & 0.14 & 0.17 & 0.09 & 0.10 & 0.09 & - & - \\
\hline Posterior teeth very well-spaced in the jaw & 1 & 0 & 0 & 0 & 0 & 1 & 1 & 1 \\
\hline Number of teeth posterior to the NAOF in the upper jaw & 1 & 0 & 1 & 0 & 0 & 0 & - & - \\
\hline Number of teeth in the upper jaw (one side) & 9 ** & 12 & 15 & 14 & 9 & 12 & - & $17-19$ \\
\hline Number of teeth in the lower jaw (one side) & 12 & 12/13" & 15 & 13 & 9 & 11 & 13 & - \\
\hline Relatively long and thin symphysis: (over $4: 1$ ) & 1 & 0 & - & 1 & 0 & 0 & 0 & - \\
\hline Long and narrow rami of the mandible in dorsal view $(20: 1)$ & 1 & - & - & 0 & 0 & - & 0 & - \\
\hline
\end{tabular}

trum, no teeth sat posterior to the NAOF and a much longer dentary symphasis.

Two species of Istiodactylus are currently known with the type species I. latidens from the UK has a partial skull and skeleton as a holotype (Howse et al., 2001; Witton, 2012), which although incomplete is preserved in three dimensions and is in excellent condition. Further material has been referred to this species and is included in the comparisons below (Howse et al., 2001). The Chinese species $I$. sinsens is based on more complete, though two dimensionally preserved material (Andres and Ji, 2006).

Istiodactylus latidens clearly differs from Luchibang in a number of features. I. latidens has labioligually compressed teeth and a small, single median tooth in the anterior mandible neither of which is seen here (Howse et al., 2011) and the former also has a much shorter and broader symphasis. Although the cristospine of the sternum in Luchibang is absent, the simple facets for the articulations for the coracoid are visible which differ from the saddle-shaped ones of I. latidens (Howse et al., 2011). The radius is strongly reduced in size in comparison to the ulna in I. latidens whereas the two elements are subequal in diameter with the ulna only being slightly larger.

Luchibang also differs from Istiodactylus sinensis in a number of characters. Unlike Luchibang, the anterior end of the rostrum of $I$. sinensis has a gentle dorsally directed curve, and the ventral edge of the maxilla under the NAOF is similarly bowed (Andres and Ji, 2006). This also has more teeth than Luchibang (15 per side of the upper and lower jaws as opposed to 12) and these are relatively evenly spaced in the jaw and not very close together anteriorly. The last tooth in the maxilla of $I$. sinensis is well separated from the penultimate tooth but this is different from the condition seen in Luchibang with a progressive and rapid increase in spaces between the more posterior teeth. Finally, I. sinensis has a femur that is close to $60 \%$ of the length of the ulna (Andres and Ji, 2008), which is similar to the $67 \%$ of Nurachius, but both are much lower than the $80 \%$ in Luchibang. We note that there are similar levels of differences between the two putative species of Istiodactylus as there are between these and between the various genera here and thus we suggest that $I$. sinensis should be separated into its own genus, a position also broadly supported by Witton (2012) for similar reasons.

The Chinese Liaoxipterus (Lü et al., 2008) is represented only by an incomplete mandible and the hyoids and of the known istiodactylids bears the most similarity to Luchibang. The spacing of the teeth is similar in both - well packed anteriorly and spreading out more posteriorly, and both have a similar number of teeth in the mandible (12 in Luchibang, but up to 13 in Liaoxipterus). They are also similar in size with the preserved symphasis of Luchibang being $56 \mathrm{~mm}$ long, and nearly $50 \mathrm{~mm}$ in 
Liaoxipterus (Lü et al., 2008). However, there are also clear differences present. The symphasysal area of Liaoxipterus this is 2.8 times as long as it is wide, but is 4.5 times longer than wide in Luchibang. The latter also possesses hyoids with a much longer anterior ramus than the posterior rami, as opposed to those of Liaoxipterus in which the posterior rami are much longer. Lü et al. (2008) described the preserved mandible as being 'nearly complete'. If so, it would be considerably smaller in absolute terms and proportionally more robust than that of Luchibang as it would be not much more than the preserved length of $150 \mathrm{~mm}$ long (compared to over 230 in a juvenile animal), while having similarly robust rami at $10 \mathrm{~mm}$ in diameter compared to $12 \mathrm{~mm}$ in the much larger Luchibang.

Despite the lack of postcranial material for a number of these taxa and the lack of the posterior part of the skull for Luchibang, this would then appear to be quite distinct from all other known istiodactylids. A number of clear characters serve to separate it from each of the other known species. Although comparisons are especially limited to the somewhat similar Liaoxipterus, even here there are several differences in the shape and extent of the symphasis, robusticity of the mandibular rami, the hyoids, and the total size of the animal.

The diagnosis of Luchibang provided above was created specifically to account for the problematic distribution of characters over the incomplete nature of various istiodactylid pterosaurs. Table 1 shows the distribution of these and some other cranial characters in istiodactylids.

Several other putative istiodactylids have also been described and are considered here briefly. The holotype and only known specimen of Hongshanopterus is a skull preserved in ventral view and some isolated vertebrae (Wang et al., 2008), so few comparisons are possible. However, Hongshanopterus has a large number of teeth in the upper jaw (15 each side) compared to Luchibang with probably only 12 , and these are evenly spaced along the tooth row and reach far back into the jaw in the former. There is no cluster of tightly packed teeth in the anterior jaw of Hongshanopterus, and the anterior jaw tips are pointed rather than rounded as in other istiodactylids including Luchibang. The teeth are also strongly compressed and with a slight recurvature at the tips in Hongshanopterus (Wang et al., 2008) unlike the conical ones seen in Luchibang. Recently it has been suggested that this taxon is not an istiodactylid but instead a member of the pteranodontoids outside of this clade (Witton, 2012) and has been recovered in analyses as a close relative of, but not within, the Istiodactylidae (Kellner et al., 2019).

The genus Haopterus (Wang and Lü, 2001) has also been proposed as an istiodactylid but has not been recovered as a member of the clade in the most recent phylogenetic analysis (Witton, 2012; Kellner et al., 2019; Zhao et al., 2019). Regardless, it is easily separated from Luchibang based on its small size (under $1.5 \mathrm{~m}$ wingspan, and considered a subadult by Wang and Lü (2001)), long, pointed, and inclined teeth, and fan-shaped sternum and further comparisons are not required.

Lü and Fucha (2010) described Archaeoistiodactylus from the Middle Jurassic of China. However, thus poorly preserved partial skull shows a number of clear traits that suggests a misidentification of the material and that it does not represent an istiodactylid but a basal monofenestratan (Sullivan et al., 2014), an argument well supported by phylogenetic analysis of Zhou et al. (2019).

Similarly, the Late Cretaceous Gwawinapterus (Arbour and Currie, 2011) from Canada was described as a new istiodactylid. It is known from only an anterior rostrum but Vullo et al. (2012) have shown that this is not a pterosaur but instead a misidentified fish.

Phylogenetic analysis. Analysis of the interrelationships of the istiodactylids is difficult as only very few specimens can be coded for more than a few characters, the available descriptions are limited, and the juvenile status of Luchibang potentially confounds this further. Even so, we carried out a simple analysis to assess the evolutionary position of Luchibang and to confirm its identity.

We took the recent and comprehensive phylogenetic analysis of pterosaur relationships by Kellner et al. (2019) and modified it with numerous characters being modified to be ordered (their 16, 22 , 46, 52, 55, 56, 60, 75, 98, 108, 110, 116, 120 , $125-127,134,135,142-148,150)$ and removing two pseudoreplicated characters (their 134 and 146-see Supplementary Data 1 for further details). We then coded the holotype of Luchibang xingzhe and the recently described istiodactylid Nurhachius luei (Zhou et al., 2019). The OTU for Linlongopterus jennyae, which was pruned in the final analyses of Kellner et al. (2019) due to its status as a "wild card taxon," was retained within our analysis for the sake of thorough sampling.

Following the addition of these changes, we performed a phylogenetic analysis with the software TNT v 1.5 (Goloboff et al., 2018) using the TBR heuristic searches performed using maximum 


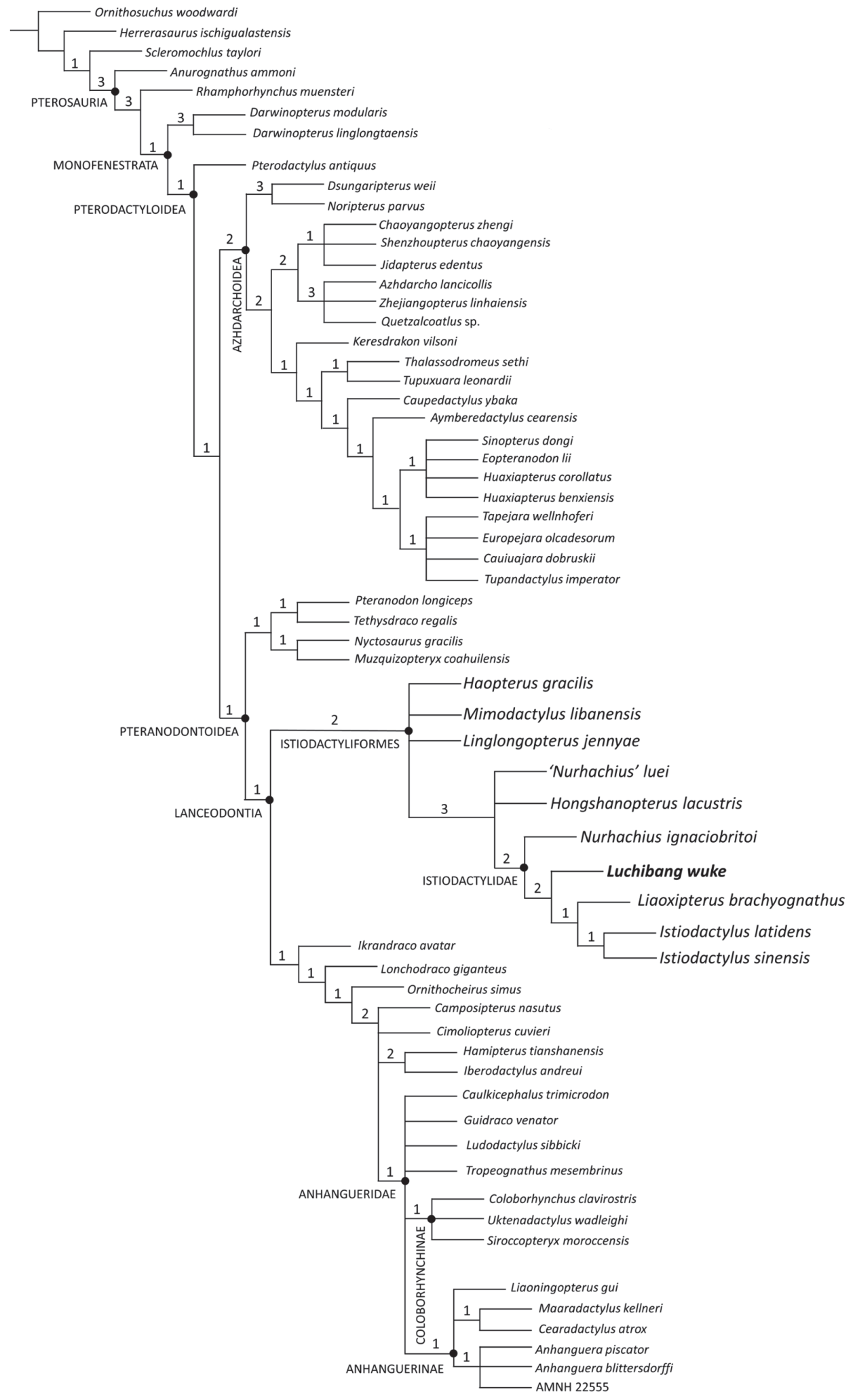

FIGURE 8. Analysis of eupterodactyloid pterosaur relationships showing the phylogenetic position of Luchibang. Major clades are labelled and numbers represent the numbers of characters (see Supplemental Data S1) that are unambiguous apomorphies of each clade (please see corrigendum). 
parsimony. Following Kellner et al. (2019), search for the most parsimonious trees (MPTs) was conducted via Traditional Search (TBR swapping algorithm), 10,000 replicates, random seed, 20 trees to save per replication, and collapsing trees after search.

\section{RESULTS}

\section{Phylogenetic Analysis}

The search performed with the full version (including cranial and postcranial anatomy) of the altered dataset from Kellner et al. (2019) including both cranial and postcranial character resulted in 60 MPTs and a strict consensus tree with a length of 365 steps (consistency index $=0.625$; retention index $=0.869$ ). Excluding the newly added taxa, the topology of the tree is nearly identical to that of Kellner et al. (2019) prior to their pruning of Linlongopterus, save the collapse of Camposipterus from a sister relationship with Anhangueria into a polytomy with Cimoliopterus, Hamipteridae, and Anhangueridae and the collapse of the Caulkicephalus, Guidraco, and Ludodactylus into a polytomy with Tropeognathus, Coloborhynchinae, and Anhanguerinae (see Figure 8).

Luchibang is recovered as the sister taxon to the Liaoxipterus-Istiodactylus clade nested within Istiodactylidae, a relationship supported by the shared possession of a rounded rostrum (char. 23) and a notably short mandibular symphysis with an anteroposterior length less than $30 \%$ of the mandible (char. 75). The Istiodactylidae, here composed of $N$. ignaciobritoi, Luchibang, Liaoxipterus, and Istiodactylus, is supported by the following characters: craniomandibular articulation anterior to the center of the orbit (char. 56), the absence of a helical jaw joint (char. 57), a strong palatal ridge confined to the posterior portion of the palate (char. 69 ), and the restriction of the dentition to the anterior quarter of the jaws (char. 86). 'Nurhachius' luei possesses a craniomandibular articular that is near the center of the orbit and dentition that extend posterior to the anterior quarter of the jaws and lacks an examinable jaw joint or palate, and so it was recovered outside of Istiodactylidae in a polytomy with Hongshanopterus and Istiodactylidae.

Istiodactyliformes is supported by the presence of labiolingually-compressed dentition (char. 97) in general, again both found in Luchibang and ' $N$.' luei. Lanceodontia is supported by presence of a pointed rostrum (char. 23), a narrow base of the lacrimal process of the jugal (char. 51), a discrete, anteriorly-tapering palatal ridge (char. 69), an odontoid process (char. 76), a stout scapula with a constructed shaft (char. 118), a deep and short cristospine on the scapula (char. 124), a small foramen on dorsal surface distal to the proximal articular surface of the humerus (char. 128), and a radius of a diameter that is less than half of the ulna (char. 134). Pteranodontoidea is supported by the presence of a pronounced ridge on the lateral ridge of the jugal (char. 53), spike-shaped mid-cervical neural spines (char. 111), suboval proximal end of the scapula (char. 117), an enlarged, warped deltopectoral crest (char. 130), a triangular distal articulation of the humerus (char. 132), a large proximodistal process on the proximal syncarpal (char. 135) with a pentagonal shape (char. 136). Of these pteranodontoid and lanceodontian synapomorphies, a stout scapula with a constructed shaft and an enlarged, warped deltopectoral crest are present in Luchibang.

It is notable that some parts of the postcranial anatomy are unexpected for an istiodactylid or pteranodontoid. The skull is much lower than other istiodactylids (skull height less than 25\% of jaw length (Zhao et al., 2019)) though this appears to simply be considerably longer than other istiodactylids. The wing metacarpal is long for an istiodactylid, the radius and ulna are similar in breadth (though this is seen in e.g., Pteranodon), the hindlimbs are unusually long (and the femur itself is long), with the pedes large and robust and metatarsal 4 is subequal to the length of the others. However, the animal is young and may have changed as it grew, and there are some postcranial traits that are entirely consistent with the specimen being an istiodactylid (or at least a pteranodontoid). As noted above, the scapulae are robust and straight and subequal or shorter than the coracoids which is normal for ornithocheiroids (Unwin, 2003), there is a warped deltopectoral crest, and the femur has a head that is near vertically orientated with the shaft. In addition, digit 1 of manual phalanx 1 is similar in length to digit 3 , phalanx 1 , which is an apomorphy of the pteranodontoids (Vidovic and Martill, 2018) and the deltopectoral crest is enlarged and warped as in other pteranodontoids, and there is a small ulnar crest to the humerus as in ornithocheirids and I. latidens (Rodrigues and Kellner, 2013). The ulna is also much longer than the humerus (1.9 times the length), which is an apomorphy of istiodactylids (Lü et al., 2010). Although crushed, the shape of the coracoid suggests it does not have a flange on the posterioventral side as seen in azhdarchoids (Frey et al., 2003b). The proportional length of the wing pha- 
lanx compared to the tibotarsus (Kellner et al., 2019 character 142) is similar to that of ornithocheiroids including Ikranodrako and Anhanguera and different to that seen in the azhdarchids (though similar to that of the tapejarid Eopteranodon). Finally, the ratio of the first and fourth wing phalanges (Kellner et al., 2019 character 145) is shared with other ornithocheiroids and pteranodontids and is different to that seen in azhdarchoids.

Given the unusual mosaic of traits we also tested only the cranial characters and only the postcranial characters in separate small analyses to confirm the validity of the material (see also Supplementary Data 2 on the validity of the specimen). The search performed with the dataset that had been modified to only examine postcranial morphology resulted in 80 MPTs and a strict consensus tree with a length of 110 (consistency index = 0.658 ; retention index $=0.874$ ). The topology outside of the pterodactyloids remains unchanged with the exception of the collapse of Scleromochlus into a polytomy with Herrerasaurus and Pterosauria. However, Pterodactyloidea is comprised of a large polytomy with the only upper level clades consisting of Pteranodontidae and Azhdarchidae + Chaoyangopterus + Jidapterus + Shenzhoupterus.

Here, the Pteranodontidae is supported by the presence of a pneumatic foramen between the distal condyles of the humerus (char. 28), the latter clade is supported by the absence of a lateral foramen on the midcervical vertebrae (char. 2), elongated mid-cervical vertebrae with a length more than three times their width (char. 3), low mid-cervical neural spine height (char. 5), the presence of a deep flange on the ventral margin of the coracoid (char. 17), and Azhdarchidae is supported by the possession of extremely elongate mid-cervical vertebrae (char. 3), extremely reduced or absent midcervical neural spines (char. 5) shaped like ridges (char. 6), wing phalanx one is shorter than the fourth metacarpal (char. 36). Of these characters 1 , 17 and 36 are observable in Luchibang but none of them match the character states see in the pteranodontoid or azhdarchid clades. Given this, the postcranium of Luchibang does appear to be, at least, of a non-pteranodontid, non-azhdarchid pterodactyloid.

\section{Limb Proportions of Pterodactyloids}

We compared the length of the humerus and the length of the hindlimb (length of femur + tibia) among a diversity of pterodactyloid pterosaurs (Figure 9) with measurements obtained from Elgin (2014 - see Supplementary Data 3 ). The humerus here is used as a proxy for body size as too few pterosaurs are complete enough to accurately measure wingspan or estimate their mass. Archaeopterodactyloids possess the smallest humeri and hindlimbs of the examined taxa, while eupterodactyloids cover a much wider range of sizes. For any given humerus size non-pteranodontid pteranodontoids possessed the shortest hindlimbs of eupterodactyloids, while pteranodontids possessed slightly longer hindlimbs and azhdarchoids possessed the longest hindlimbs. Only one istiodactylid was complete enough for inclusion in this analysis (Nurhachius) and it plots similarly to other pteranodontoids. However, Luchibang has proportionally longer limbs, plotting among azhdarchoids in limb proportions despite its clearly pteranodontoid affinities.

\section{DISCUSSION}

\section{Istiodactylid ecology}

A variety of ecological roles have been suggested for the istiodactylids in the past. The robust but pointed teeth with a 'cookie-cutter' like rounded jaw tip are quite specialised compared to other pterosaurs (Figure 2). The relative rarity of specimens of istiodactylids suggests that they were quite a rare component of Cretaceous ecosystems. They have been suggested to be scavengers (Howse et al., 2001; Witton, 2012), piscovores (Howse et al., 2001), suspension feeders (Fastnacht, 2005), and even insectivory in the case of Liaoxipterus (Lü et al., 2008). Additional information here actually provides some limited support for both of the two former hypotheses.

First there is the preserved gut content. At the ventral edge of the sternum on the left hand side, a small fish is preserved underneath a gastralium (Figure 5). This would appear to be inside the body cavity and in the region where the gut would likely lie in life suggesting that this represents true gut content. However, it is only a small fish (just a few $\mathrm{cm}$ long) and would not seem to be large enough to be a major part of the diet of an animal this size unless a great many were eaten at a time. Moreover, the presence of a second fish skeleton close to the head (Figure 2), and other invading elements on the slab (such as the odd strips of bone near the NAOF), suggests that other pieces of other animals, or even plants, were preserved with this specimen. The 'gut' fish then may be a chance association of a fish that happens to be under a gastralium. The long limbs and especially the large feet of Luchibang may have made this animal 


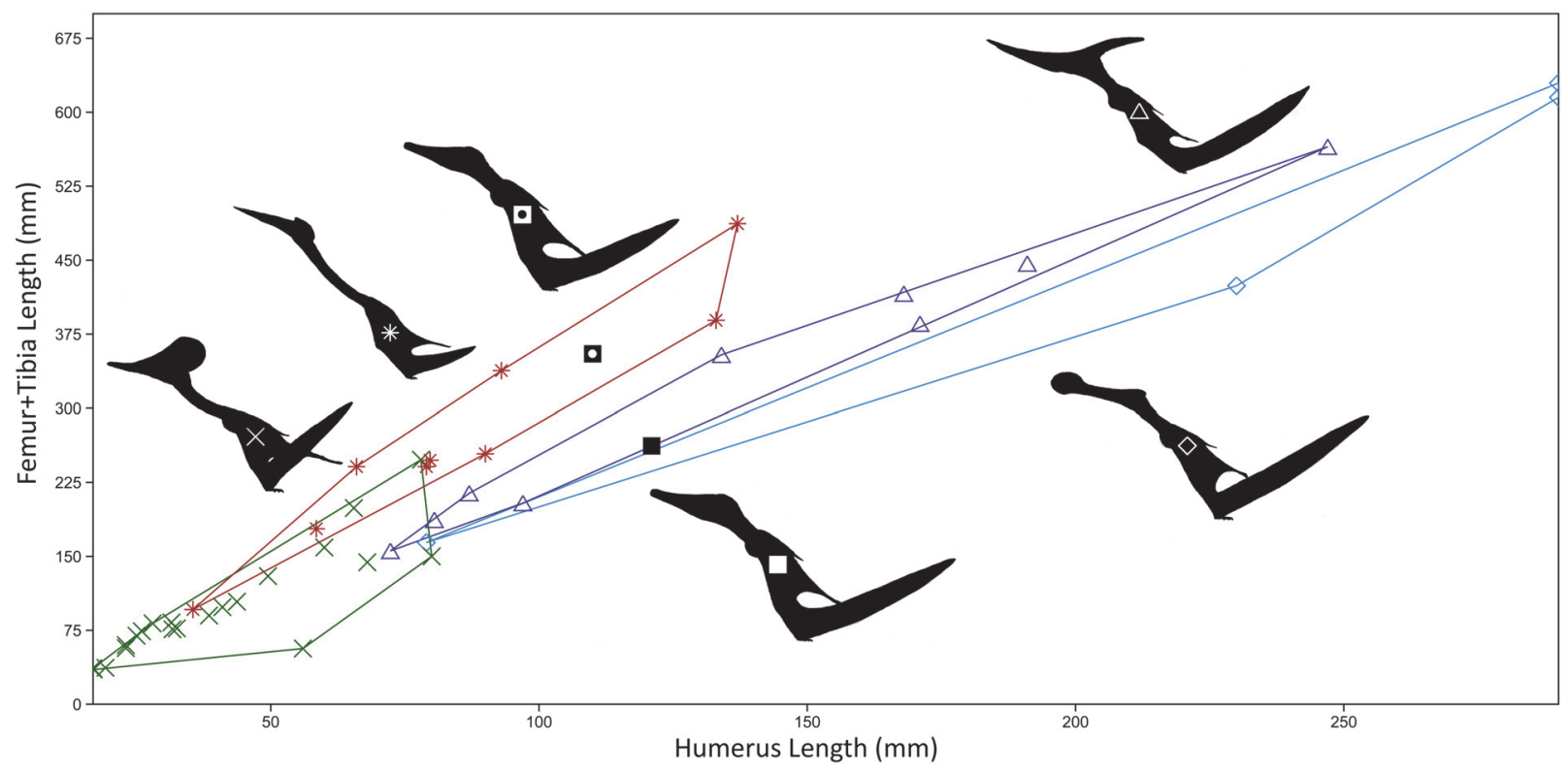

FIGURE 9. Analysis of pterosaur limbs proportions comparing humerus length to hindlimb length. Istiodactylids are represented by squares, ornithocheirids by diamonds, pteranodontids by triangles, ctenochasmatids by crosses, and azhdarchoids by asterisks. Luchibang is represented by a square containing a circle. Silhouettes courtesy of, and used with permission from, Mark Witton.

potentially good at foraging at the margins of bodies of water, but also potentially make it good on hard ground as well.

Witton (2012) suggested that istiodactylids generally may have been more terrestrially adapted than other pteranodontoids and have been less adapted to aquatic take off or long flights. It is also notable that istiodactylid taxa are mostly known from freshwater deposits and often from locations that were well inland unlike most pteranodontoids. Luchibang is notable in being perhaps the best adapted of the istiodactylids to a terrestrial lifestyle given the long hindlimbs (Figure 9) and large feet. In many pteranodontoids (e.g., Pteranodon, Anhanguera) are widely considered pelagic piscivores (e.g., see Unwin, 2005) and are characterised in part by their reduced hindlimbs and hypothesised poor terrestrial locomotive capabilities (Witton and Habib, 2010) since they presumably spent little time on the ground. This contrasts with the largely terrestrial azhdarchids (Witton and Naish, 2008), which hail from terrestrial deposits and, like Luchibang, are characterised by long hindlimbs and large pedes.

The proportions of the hind limbs suggest that Luchibang at least was more capable terrestrially than other istiodactylids and may have spent a significant amount of time on the ground as would perhaps be expected for a predator or scavenger.
The long hindlimbs of Luchibang may also have changed the flight profile of the animal giving it a broad wing planform compared to other istiodactylids. The pterosaur brachiopatagum attached to the ankle (Elgin et al., 2011) and although this does not necessarily mean that a long-legged animal had a deeper chord to the wing, it does at least raise the possibility. Witton (2013) noted the istiodactylids potentially had more broad wings that other ornithocheirids, but this would be exaggerated considerably in Luchibang. A low aspect ratio wing with a lower wing loading would make it potentially better adapted to fly in an inland environment in contrast to other pteranodontoids and could support a scavenging lifestyle with the ability to move long distances efficiently.

Suspension feeding is not supported as the teeth are relatively few, robust, and large (and in some taxa well-spaced posteriorly), which lies in contrast to the classic filter-feeding apparatus of numerous, long, thin, and closely packed teeth (see also Witton, 2012). However, although the teeth of istiodactylids are considered to be sharp edged (Witton, 2012) this is not true of Luchibang or Liaoxipterus, which both have more rounded teeth suggesting that these at least are not so well adapted to cut food such as meat on a carcass.

Insectivory was suggested by Lü et al. (2008) for Liaoxipterus based on an enlarged hyoid appa- 
ratus that was supposedly similar to that of chameleons thus supporting lingual feeding. However, such a hyoid shape is seen in many long-skulled pterosaurs (e.g., see Frey et al., 2003a; Wang et al., 2005; Lü et al., 2010). and the shape of the hyoid is not similar to Chamaeleo, which has an especially long anterior ramus, and the whole bone is T-shaped unlike the gentle Y-shaped posterior expansion seen in pterosaurs. While large insects are present in the Yixian Formation, Liaoxipterus was a large pterodactyloid (and much larger than modern insectivorous birds or bats). Furthermore, what little is known of the anatomy of taxon is not dramatically different to other istiodactylids so it is not clear why the interpretation of insectivory should be favoured for this genus alone. Insectivory is therefore not supported.

In conclusion, Luchibang provides limited support for both scavenging and piscivory, though evidence for the latter may be a result of chance association. As with a number of previous authors (e.g., Howse et al., 2001; Unwin, 2005; Witton, 2012) therefore, we conclude that scavenging may well have formed a major part of the diet of istiodactylids. This could be investigated in the future with both functional studies of istiodactylid skulls, and also examination of microwear patterns on the teeth, which could indicate a diet of flesh or fish.

\section{Skin}

Several patches of soft tissues are identified here as likely representing the skin of the pterosaur given their positions on the specimen. These are not likely patches of muscle or other body tissues and do not look like such dissociated/dissolved areas seen in other Yixian specimens (e.g., see Hone et al., 2010, on the soft tissue preservation of the dromaeosaurid dinosaur Microraptor gui). However, the presence of skin on such a pterosaur specimen is somewhat unusual. In pterosaur species preserving soft tissues, the wings (especially the distal tips with large numbers of actinofibrils) and the pycnofibers are generally more common (e.g., Frey et al., 2003a; Elgin et al., 2011; Kellner et al., 2009) than skin, but no fibers are seen here.
While a number of pterosaurs are known with extensive pycnofiber coverage (Unwin, 2005; Kellner et al., 2009) little material has been reported that may represent pterosaur skin from the body (Kellner 1996) as opposed to a specialised tissue type such as wing membranes, foot webbing, throat pouches, etc. Even specimens of exceptional preservation lack skin, the Jeholopterus holotype for example, preserves numerous pycnofibers and all wing membranes, but only some small parts were tentatively identified as dermis/ epidermis (Kellner et al., 2009). The pieces seen on ELDM 1000 represent by far the largest amount of pterosaur skin yet identified, and if this identification is correct, it suggests that large parts of the skin of Luchibang may have lacked pycnofibers.

This may be less odd that it first appears certainly some large birds have patches of skin with few or no feathers (e.g., Struthio, Vultur, Geronticus, Acryllium, Ajaja) and notably including several scavengers and waders (and in the case of Leptoptilos, both). More simply given the rarity of pterosaur skin it seems plausible that many pterosaurs had patches of skin free of pycnofibers but these have simply not been preserved, or perhaps even lost through preparation as has likely happened to other pterosaur soft tissue bearing specimens (Elgin et al., 2010).

\section{ACKNOWLEDGEMENTS}

We thank L. Steel for access to material at the NHM and discussion of istiodactylid material. Thanks to Z. Fang for access to IVPP material, and L. Junchang for examination of the Liaoxipterus holotype. M. Witton is thanked for discussion of istiodactylid taxonomy and B. Andres for photographs of the I. sinensis material. M. Van Rooijen is thanked for assistance with the figures and M. Witton for permission to use his material for Figure 9. Special thanks to $C$. Rodgers for independent examination and preparation of the specimen. This study was supported by the National Natural Science Foundation of China (Grant No. 41688103 and 91514302 and 41120124002$)$. We thank two anonymous referees for their comments which helped improve this manuscript. 


\section{REFERENCES}

Andres, B. and Ji, Q. 2006. A new species of Istiodactylus (Pterosauria, Pterodactyloidea) from the Lower Cretaceous of Liaoning, China. Journal of Vertebrate Paleontology, 26:70-78. https://doi.org/10.1671/0272-4634(2006)26[70:ANSOIP]2.0.CO;2

Andres, B. and Ji, Q. 2008. A new pterosaur from the Liaoning Province of China, the phylogeny of the Pterodactyloidea, and the convergence in their cervical vertebrae. Palaeontology, 51:453-469. https://doi.org/10.1111/j.1475-4983.2008.00761.x

Arbour, V.M. and Currie, P.J. 2011. An istiodactylid pterosaur from the Upper Cretaceous Nanaimo Group, Hornby Island, British Columbia, Canada. Canadian Journal of Earth Sciences, 48:63-69. https://doi.org/10.1139/e10-083

Bennett, S.C. 1995. A statistical study of Rhamphorhynchus from the Solnhofen limestone of Germany: Year-classes of a single large species. Journal of Paleontology, 69:569-580. https://doi.org/10.1017/s0022336000034946

Bennett, S.C. 1996. Year-classes of pterosaurs from the Solnhofen Limestone of Germany: Taxonomic and systematic implications. Journal of Vertebrate Paleontology, 16:432-444. https://doi.org/10.1080/02724634.1996.10011332

Bennett, S.C. 2001. The osteology and functional morphology of the Late Cretaceous pterosaur Pteranodon. Palaeontographica A, 260:1-153.

Benson, R.B., Butler, R.J., Carrano, M.T., and O'Connor, P.M. 2012, Air?filled postcranial bones in theropod dinosaurs: physiological implications and the 'reptile'-bird transition. Biological Reviews, 87:168-193.

Dong, Z., Sun, Y., and Wu, S. 2003. On a new pterosaur from the Lower Cretaceous of Chaoyang Basin, Western Liaoning, China. Global Geology, 22:1-7.

Elgin, R.A. 2014. Palaeobiology, morphology, and flight characteristics of pterodactyloid pterosaurs. PhD Thesis, University of Heidelberg, Germany.

Elgin, R.A., Hone, D.W.E., and Frey, E. 2011. The extent of the pterosaur flight membrane. Acta Palaeontologica Polonica, 56:99-111. https://doi.org/10.4202/app.2009.0145

Fastnacht, M. 2005. Jaw mechanics of the pterosaur skull construction and the evolution of toothlessness. PhD Thesis, Johannes Gutenberg-Universität Mainz, Germany.

Frey, E., Tischlinger, H., Buchy, M.-C., and Martill, D.M. 2003a. New specimens of Pterosauria (Reptilia) with soft parts with implications for pterosaurian anatomy and locomotion. Geological Society Special Publications, 217:233-266. https://doi.org/10.1144/ gsl.sp.2003.217.01.14

Frey, E., Buchy, M.-C., and Martill, D.M. 2003b. Middle- and bottom-decker Cretaceous pterosaurs: unique designs in active flying vertebrates. Geological Society Special Publications, 217:267-274. https://doi.org/10.1144/gsl.sp.2003.217.01.15

Goloboff, P.A., Farris, J.S., and Nixon, K.C. 2008. TNT, a free program for phylogenetic analysis. Cladistics, 24:774-786. https://doi.org/10.1111/j.1096-0031.2008.00217.x

Hone, D.W.E. and Lü, J.-C., 2010, A new specimen of Dendrorhynchoides (Pterosauria: Anurognathidae) with a long tail and the evolution of the pterosaurian tail. Acta Geoscientica Sinica, 31:29-30.

Hone, D.W.E., Tischlinger, H., Xu, X., and Zhang, F.-C. 2010. The extent of the preserved feathers on the four-winged dinosaur, Microraptor gui under ultraviolet light. PLoS One, 5:e9223. https://doi.org/10.1371/journal.pone.0009223

Howse, S.C.B., Milner, A.R., and Martill, D.M. 2001. Pterosaurs, p. 324-335. In Martill, D.M. and Naish, D. (eds.), Dinosaurs of the Isle of Wight. Palaeontological Association, Field Guide to Fossils, 10:324-335.

Hyder, E.S., Witton, M.P., and Martill, D.M. 2014. Evolution of the pterosaur pelvis. Acta Palaeontologica Polonica, 59:109-124. https://doi.org/10.4202/app.2011.1109

Kaup, J.J. 1834. Versuch einer Eintheilung der Saugethiere in 6 Stämme und der Amphibien in 6 Ordnungen. Isis, 3:311-315.

Kellner, A.W.A. 1996. Reinterpretation of a remarkably well preserved pterosaur soft tissue from the Early Cretaceous of Brazil. Journal of Vertebrate Paleontology, 16:718-722. https:// doi.org/10.1080/02724634.1996.10011360 
Kellner, A.W.A. 2003. Pterosaur phylogeny and comments on the evolutionary history of the group. Geological Society Special Publications, 217:105-137. https://doi.org/10.1144/ gsl.sp.2003.217.01.10

Kellner, A.W.A. 2015. Comments on Triassic pterosaurs with discussion about ontogeny and description of new taxa. Anais da Academia Brasileira de Ciências, 87:669-689. https:// doi.org/10.1590/0001-3765201520150307

Kellner, A.W.A. and Tomida, Y. 2000. Description of a new species of Anhangueridae (Pterodactyloidea) with comments on the pterosaur fauna from the Santana Formation (Aptian-Albian), northeastern Brazil. National Science Museum Monographs, 17:1-135.

Kellner, A.W.A., Wang, X.-L., Tischlinger, H., Campos, D.A., Hone, D.W.E., and Meng, X. 2009. The soft tissue of Jeholopterus (Pterosauria, Anurognathidae, Batrachognathidae) and the structure of the pterosaur wing membrane. Proceedings of the Royal Society, Series B, 277:321-329. https://doi.org/10.1098/rspb.2009.0846

Kellner, A.W., Caldwell, M.W., Holgado, B., Dalla Vecchia, F.M., Nohra, R., Sayão, J.M., and Currie, P.J. 2019. First complete pterosaur from the Afro-Arabian continent: insight into pterodactyloid diversity. Scientific Reports, 9:1-9. https://doi.org/10.1038/s41598-019-54042$z$

Lü, J.C. and Fucha, X.H. 2010. A new pterosaur (Pterosauria) from the Middle Jurassic Tiaojishan Formation of western Liaoning, China. Global Geology, 13:113-118.

Lü, J.C., Ji, S., Yuan, C., and Ji, Q. 2006. Pterosaurs from China. Geological Publishing House, Beijing.

Lü, J.C., Xu, L., and Ji, Q. 2008. Restudy of Liaoxipterus (Istiodactylidae: Pterosauria) with comments on the Chinese istiodactylid pterosaurs. Zitteliana B, 28:229-241.

Lü, J.C., Unwin, D.M., Jin, X., Liu, Y., and Ji, Q. 2010. Evidence for modular evolution in a longtailed pterosaur with a pterodactyloid skull. Proceedings of the Royal Society, Series B, 277:383-389. https://doi.org/10.1098/rspb.2009.1603

Lü, J.C., Xu, L., Chang, H., Zhang, X. 2011. A new darwinopterid pterosaur from the Middle Jurassic of Western Liaoning, northeastern China and its ecological implications. Acta Geologica Sinica, 85:507-514. https://doi.org/10.1111/j.1755-6724.2011.00444.x

Lü, J.C., Pu, H., Xu, L., Wu, Y., and Wei, X. 2012. Largest toothed pterosaur skull from the Early Cretaceous Yixian Formation of Western Liaoning, China, with comments on the family Boreopteridae. Acta Geologica Sinica, 86:287-293. https://doi.org/10.1111/j.17556724.2012.00658.x

Plieninger, F. 1901. Beiträge zur Kenntnis der Flugsaurier. Palaeontographica, 41:193-222.

Rodrigues, T. and Kellner, A.W.A. 2013. Taxonomic review of the Ornithocheirus complex (Pterosauria) from the Cretaceous of England. ZooKeys, 308:1-112. https://doi.org/10.3897/ zookeys.308.5559

Sullivan, C., Wang, Y., Hone, D.W., Wang, Y., Xu, X., and Zhang, F. 2014. The vertebrates of the Jurassic Daohugou Biota of northeastern China. Journal of Vertebrate Paleontology, 34:243280. https://doi.org/10.1080/02724634.2013.787316

Unwin, D.M. 2003. On the phylogeny and evolutionary history of pterosaurs. Geological Society Special Publications, 217:139-190. https://doi.org/10.1144/gsl.sp.2003.217.01.11

Unwin, D.M. 2005. The Pterosaurs from Deep Time. Pi Press, New York.

Vidovic, S.U. and Martill, D.M. 2018. The taxonomy and phylogeny of Diopecephalus kochi (Wagner, 1837) and 'Germanodactylus rhamphastinus' (Wagner, 1851). Geological Society, London, Special Publications, 455:125-147. https://doi.org/10.1144/sp455.12

Vullo, R., Buffetaut, E., and Everhart, M.J. 2012. Reappraisal of Gwawinapterus beardi from the Late Cretaceous of Canada: a saurodontid fish, not a pterosaur. Journal of Vertebrate Paleontology, 32:1198-1201. https://doi.org/10.1080/02724634.2012.681078

Wang, X.L., and Lü, J.C. 2001. Discovery of a pterodactylid pterosaur from the Yixian Formation of western Liaoning, China. Chinese Science Bulletin, 46:1112-1117. https://doi.org/10.1007/ bf02900690

Wang, X.-L., Kellner, A.W.A., Zhou, Z.-H., and Campos, D.A. 2005. Pterosaur diversity and faunal turnover in Cretaceous terrestrial ecosystems in China. Nature, 437:875-879. https:// doi.org/10.1038/nature03982

Wang, L., Li, L., Duan, Y., and Cheng, S.-L. 2006. A new iodactylid pterosaur from western Liaoning, China. Geological Bulletin of China, 25:737-740. 
Wang, X., Campos, D.A., Zhou, Z.-H., and Kellner, A.W.A. 2008. A primitive istiodactylid pterosaur (Pterodactyloidea) from the Jiufotang Formation (Early Cretaceous), northeast China. Zootaxa, 18:1-18. https://doi.org/10.11646/zootaxa.1813.1.1

Witton, M. and Habib, M. 2010. On the size and flight diversity of giant pterosaurs, the use of birds as pterosaur analogues and comments on pterosaur flightlessness. PLoS One, 5:e13982. https://doi.org/10.1371/journal.pone.0013982

Witton, M.P. and Naish, D. 2008. A reappraisal of azhdarchid pterosaur functional morphology and paleoecology. PLoS One, 3:e2271. https://doi.org/10.1371/journal.pone.0002271

Zheng, X., O'Connor, J.K., Wang, X., Pan, Y., Wang, Y., Wang, M., and Zhou, Z. 2017. Exceptional preservation of soft tissue in a new specimen of Eoconfuciusornis and its biological implications. National Science Review, 4:441-452. https://doi.org/10.1093/nsr/ nwx004

Zhou, Z.-H., Barrett, P.M., and Hilton, J. 2003. An exceptionally preserved Lower Cretaceous ecosystem. Nature, 421:807-814. https://doi.org/10.1038/nature01420

Zhou, X., Pêgas, R.V., Leal, M.E., and Bonde, N. 2019. Nurhachius luei, a new istiodactylid pterosaur (Pterosauria, Pterodactyloidea) from the Early Cretaceous Jiufotang Formation of Chaoyang City, Liaoning Province (China) and comments on the Istiodactylidae. PeerJ, 7:e7688. https://doi.org/10.7717/peerj.7688 


\section{SUPPLEMENTAL DATA}

\section{S1.1. Changes to the Kellner et al. (2019) Matrix:}

The matrix of Kellner et al. (2019) was the basis of the phylogenetic analysis of this study, but a number of changes were made to the matrix used here. All provided numbers corresponding to character numberings in the new matrix are provided in italics and within parentheses.

Some characters in the original matrix were pseudoreplicates and so removed. Characters 134 was a pseudoreplicate of characters 125 (125), 126 (126), and 127 (127), and Character 146 was a pseudoreplicate of characters 144 (143) and 145 (144).

A number of characters should be considered ordered because they transition through multiple states (e.g. short > medium > large). However, these characters were left unordered in the original matrix, and so they were specified as ordered in the altered matrix used here. These characters were as follows: their $16,22,46,52,55,56,60,75,98,108,110,116,120,125,126,127$, $134,135,142,143,144,145,146,147,148$, and $150(16,22,46,52,55,56,60,75,98,108$, $110,116,120,125,126,127,134,140,141,142,143,144,145,146$, and 148, respectively).

S1.2. TNT Data Matrix for Total (Cranial \& Postcranial) Phylogenetic Analysis of Hone et al., (2020):

xread

15063

Ornithosuchus_woodwardi 00000020000010001000000100000-00000-00--0100---000000000000--0-0000000000?0000000--00-

000000000000000000000000000000000000000000000000000000000000000

Herrerasaurus_ischigualastensis 00001000000000001000000100000-00000-00--0100---000000000000--0-000000000000000000--00-

000000000000000000000000000000000000000000000000000000000000020

Scleromochlus_taylori 00001000000000001000020100000-00000--

00--0100---00001?020??0--0-00????0000000?0000--00-

00?000?000??000000???00??0000??0?000???00??0???0???00?0000000??

Anurognathus_ammoni 00000010000000001100120100000-00100--

00--0110---000110010??0--0-000000000100000000--00-

$001000100100000000 ? ? ? 0 ? ? ? 01000 ? 0 ? ? ? 0 ? ? 0110 ? 100000 ? ? 1001122 ? 0011$

Rhamphorhynchus_muensteri 11001000000110010100001300000-00000-00--0100---000000021000--0-000000001002012010--00-

$00100010000001000000000000010000010001111002000100 ? 100122221012$

Darwinopterus_linglongtaensis 1011000000011??????0001100000-

0000?20000000-1010100010021?00--0-00?00?00????010000--00-

$0010001 ? 1000000000 ? ? ? 10 ? ? 001 ? 0 ? 00 ? 000 ? 1110 ? 100 ? 10 ? ? 100311111022$

Darwinopterus_robustodens 101100?00?011??????0001100000-

0000?20000000-1010?00010021?00--0-00?00?00????010000--00-

$0010001 ? 1000000000 ? ? ? 1 ? ? ? 001 ? 0 ? 00 ? ? 0 ? ? 111 ? ? 100 ? 10 ? ? 10031111102 ?$

Pterodactylus_antiquus 1010000000011??0???0001100000-00000-00--00-1001000010031?00--0-10?00000???2010000--00-

$0010001010000000000002110010000001000121100500 ? 100 ? 100312222020$

Dsungaripterus_weii 10100001011110411200001300000-

0100111000010-?---0000100211012211011101001012012000--11-12--

$011000000000001111100110 ? 000 ? ? ? 0 ? 2210 ? ? 5 ? 001001 ? ? 13122 ? 2120$

Noripterus_parvus 1010000101111??????0001300000-

0100111000010-?---000010021?01221101?10?00?0?2012000--?1-12--

01100000000000?11??0??????????????????????0?001????????????

Keresdrakon_vilsoni 101????????????????00?1300000-?00?0--

00--?0-???????????2????????????0000???301200101?3

?111?00?????00020011?0?01520?1??????????????? 


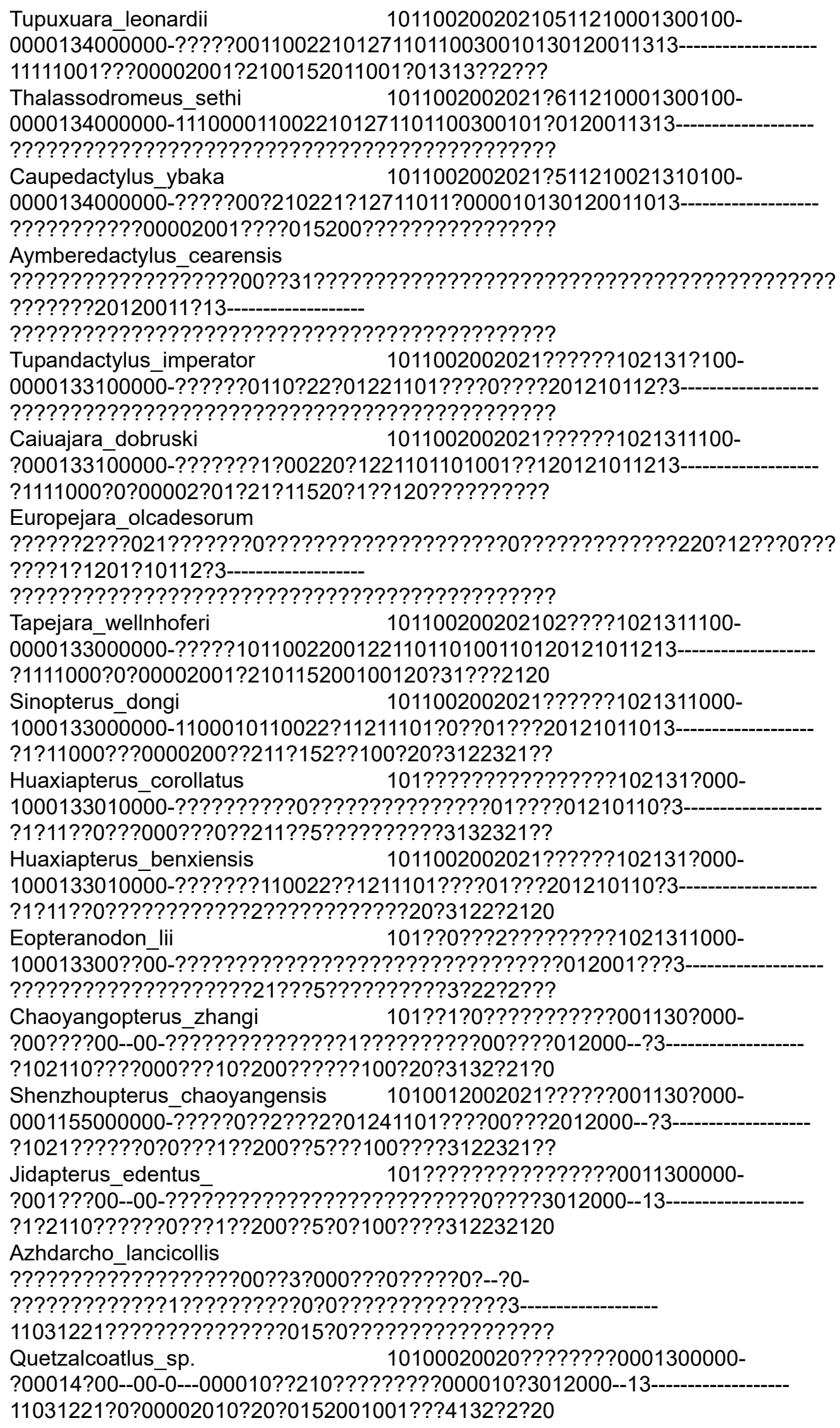




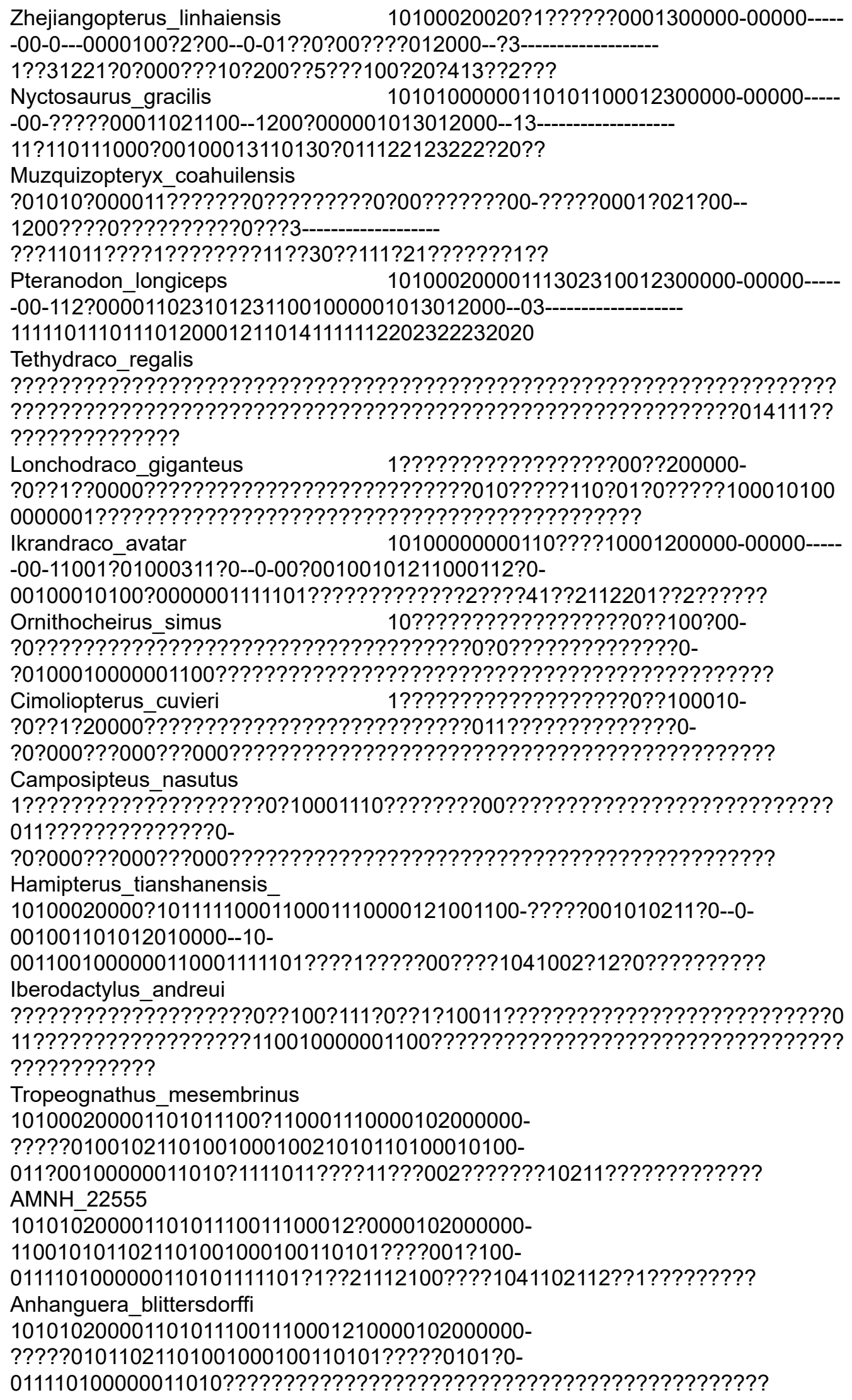




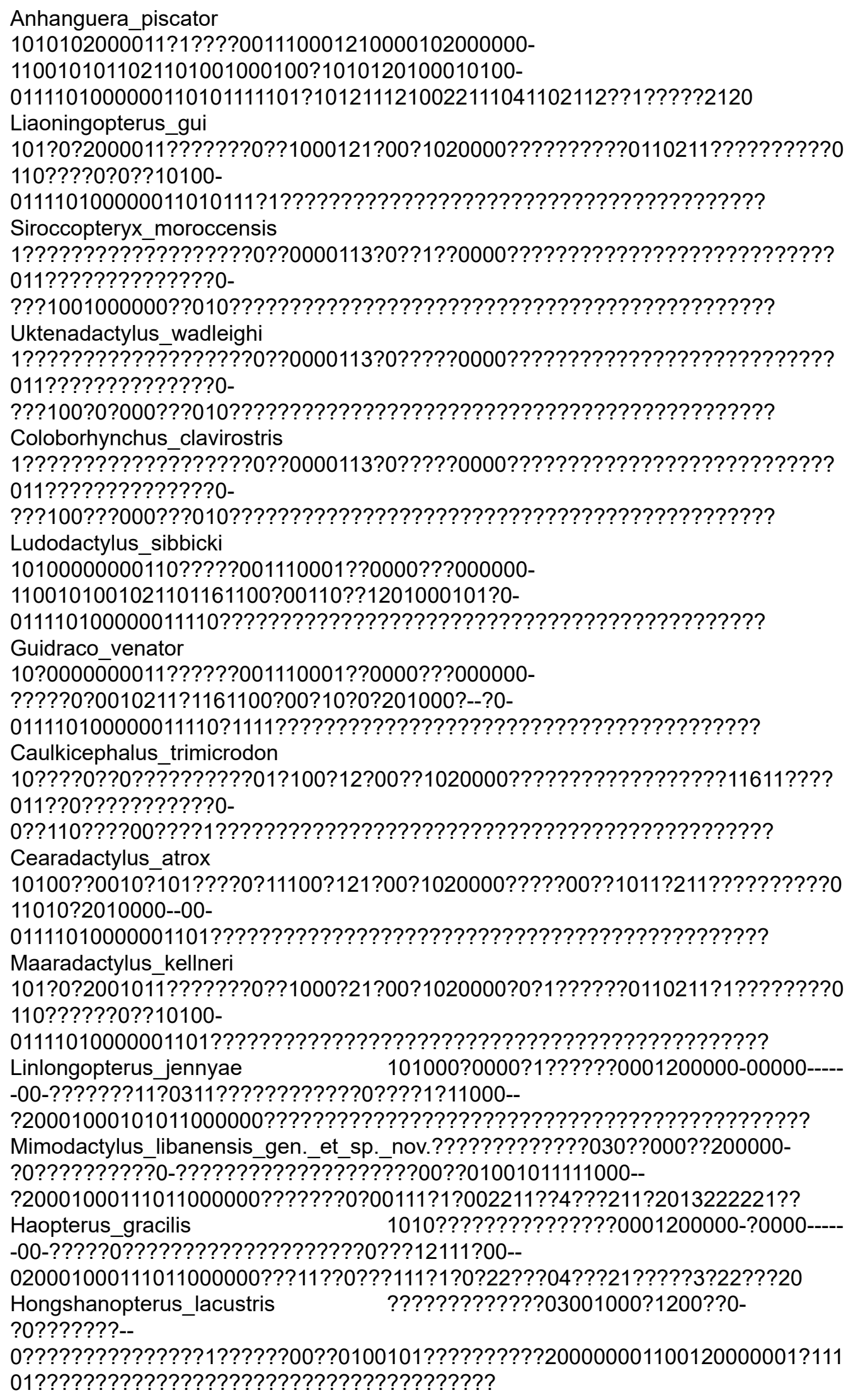


Liaoxipterus_brachyognathus

????????????????????0??1????????????????????????????????????????????

??0????1?10000--

?21?00000110012000000????????????????????????????????????????????

Istiodactylus latidens 1011000111111??????0000100010-00000

00-11100011211330?0--0-001?0?00?011110000--

?21000000110012100000?111?011???111020002?1?10411?2112???????????

Istiodactylus_sinensis

1011000111111??????0000100010-00000-----

00-?????011211330?0--0-00?00300???111?000--

?210000001100121000001??11??1???1?1???0??21???4???211???13122??1??

Nurhachius_ignaciobritoi 10110020?10?1??????0001200010-00000----00-??1??01111033000--??????0300?0?2111000--

?21000000110012000000??111011???1?10200?2211?041??2112??1312??21??

Nurhachius_luei 1011002001?11??????0001200010-00000----

-00-0----0????031?00----?0?????????2111000--

?20000000110012000000?1?110?????????????????????????????????????

Luchibang_wuke 101???????????????000?0000?0-?00?0---

$-00-$

???????????????????????????????1?1100????21000000110012000000?1?11??? ?????102000?201??40??1??????212222120

cnames

\{0 External_naris_(or_nasoantorbital_fenestra),_position_relative_to_the_premaxilla_ main_part_dorsal_to_the_ventral_margin_of_the_premaxilla main_part_dis-

placed_posterior_to_the_premaxilla;

\{1 External_naris,_dorsoventrally_compressed absent present;

\{2 External_naris_and_antorbital_fenestra,_configuration_separated confluent,_forming_a_nasoantorbital_fenestra;

\{3 External_naris_and_antorbital_fenestra_(or_nasoantorbital_fenestra),_ventral_margin_length_relati ve_the_skull_length shorter_than_40\%_of_the_skull_length_longer_than $40 \%$ of the skull_length;

$\{4$ Antorbital_(or_nasoantorbital)_fenestra,_posterior_margin,_shape_straight_concave;

\{5 Nasoantorbital_(or_antorbital)_fenestra_extending_dorsal_to_the_orbit_absent present;

\{6 Orbit,_shape_subcircular quadrangular_(broad_base) piriform_(dorsoventral-

ly_elongated)_;

$\{7$ Orbit,_comparatively_small absent_present_;

$\{8$ Ventral_margin_of_the_orbit closed open;

\{9 Orbit,_position

middle_of_the_skull,_with_the_ventral_margin_of_the_orbit_below_the_middle_of th e_antorbital_(or_nasoantorbital)_fenestra_and_the_dorsal_margin_of_the_orbit_abov e_the_dorsal_margin_of_the_antorbital_(or_nasoantorbital)_fenestra high_in_the _skull, _with_the _ventral_margin_of the _orbit the same_level_or_above_the_middle of the _antorbital_(or_nasoantorbital)_fenestra low_in_the_-

skull,_with_the_entire_orbit_lower_than_the_dorsal_margin_of_the_antorbital_(or_nasoantorbital)_fenestra;

$\{10$ Suborbital_opening absent_present ;

\{11 Lower_temporal_fenestra,_shape_comparatively_broad,_with_extensive_subhorizontal_ventral_margin piriform,_with_dorsal_portion_wider_than_ventral

reduced_(slit-like);

\{12 Lower_temporal_fenestra,_position_relative_to_orbit posterior_to_orbit

reaches_under_posterior_margin_of_orbit;

$\{13$ Choanae,_separation separated_by_vomer confluent; 
\{14 Postpalatine_fenestra,_shape_quadrangular/subtriangular oval egg-shaped elongated_eggshaped_kite-shaped,_rounded_margin elliptical reduced,_slit-like;

$\{15$ Secondary_subtemporal_fenestra absent present;

\{16 Interpterygoid_fenestra,_size_ORDERED extremely_reduced smaller_than_subtemporal_fenestra larger_than_subtemporal_fenestra;

$\{17$ Interpterygoid_fenestra,_shape_compressed_laterally broad,_longer_than_wide compressed_anteroposteriorly,_wider_than_long round;

$\{18$ Pterygoid_fenestra absent_present;

$\{19$ Upper_and_lower_jaw,_marked_gap_during_occlusion absent_present;

$\{20$ Upper_and_lower_jaw,_shape laterally_compressed_comparatively_broad_;

\{21 Skull,_main_part_of_dorsal_margin,_curvature_excluding_cranial_crest near-

ly_straight concave_convex;

\{22 Length_of_the_rostrum_(pm-naof)_relative_to_the_skull_length_(pm-sq)_OR-

DERED reduced_elongated_(about_or_less_than_half_of_skull_length)_extreme-

ly_elongated_(more_than_half_of_skull_length);

$\{23$ Rostrum,_anterior_end,_shape_flat_surface rounded pointed sharp_tip;

\{24 Rostral_end_of_premaxillae/maxillae_downturned absent_present_;

$\{25$ Rostrum,_distinct_concavity_on_occlusal_surface absent present;

\{26 Rostrum,_anterior_portion_forming_a_high_ossified_plate absent present;

$\{27$ Rostrum,_anterior_tip_with_a_slight_dorsal_reflection absent present;

\{28 Premaxilla,_anterior_expansion absent present;

$\{29$ Premaxilla,_anterior_expansion,_shape_in_horizantal_plane_absent elliptical

anteriorly_expanded quadrangular;

\{30 Premaxilla,_posterior_dorsal_process,_curved_upward absent present;

\{31 Premaxillae,_anterior_end_rodlike absent present;

\{32 Premaxillary_process_separating_the_external_nares,_thickness_wide narrow_;

\{33 Premaxilla,_posterodorsal_margin_of_nasoantorbital_fenestra_(including_na-

sal),_width_wide thin;

\{34 Premaxillary_sagittal_crest absent present;

\{35 Premaxillary_sagittal_crest_position confined_to_the_anterior_portion_of_the_-

skull_starting_anterior_to_the_anterior_margin_of_the_nasoantorbital_fenestra,_ex-

tending_beyond_occipital_region

starting_at_about_the_anterior_margin_of_the_nasoantorbital_fenestra,_reaching_the _skull_roof_above_the_orbit_but_not_extending_over_the_occipital_region

starting_close_or_at_the_anterior_portion_of_the_skull_and_extended_over_the_occi pital_region starting_at_the_posterior_half_of_the_nasoantorbital_fenestra starting_at_the_middle_part_of_the_nasoantorbital_fenestra_and_extended_over_the occipital_region_;

\{36 Premaxillary_sagittal_crest,_shape striated,_low_with_a_nearly_straight_dorsal_margin striated,_high_with_a_nearly_straight_dorsal_margin round_dorsal_mar-

gin,_bladeshaped smooth,_expanded_anteriorly_and_forming_a_low_rod-

like_extension_posteriorly smooth,_starting_low_anteriorly_and_very_expanded_pos-

teriorly striated,_low,_convex_dorsal_margin;

$\{37$ Premaxillary_crest,_elongated_dorsal_premaxillary_spike-like_projection_

absent_present_;

\{38 Premaxillary_crest,_distinct_expansion_on_the_anterior_part_absent present;

$\{39$ Premaxillary_crest,_concentric_striae_on_the_anterior_region absent present;

\{40 Premaxillary_crest,_anterior_expansion_of_the_anterior_margin absent present;

\{41 Maxilla,_posterior_ventral_expansion_absent_present_;

\{42 Maxilla-nasal_contact absent present;

\{43 Maxilla-nasal_contact,_broadness broad narrow;

\{44 Nasal_descending_process absent present;

\{45 Nasal_descending_process,_position_placed_laterally placed_medially absent; 
\{46 Nasal_descending_process,_length_long_(almost_reaching_the_ventral_margin_of_the_skull)_ORDERED short knob-like_(extremely_reduced) absent;

$\{47$ Nasal_descending_process,_orientation_inclined_anteriorly subvertical;

\{48 Nasal_descending_process,_lateral_foramen_absent_present_;

$\{49$ Lacrimal,_extensive_fenestration absent_present_;

\{50 Lacrimal,_orbital_process_absent_present_;

$\{51$ Jugal,_lacrimal_process_base,_width_broad narrow;

\{52 Jugal,_lacrimal_process,_inclination_ORDERED inclined_anteriorly subvertical inclined_posteriorly;

\{53 Jugal,_presence_of_pronounced_ridge_on_the_lateral_side absent present;

$\{54$ Jugal,_posterior_process,_orbital_process absent present;

\{55 Quadrate,_inclination_relative_to_ventral_margin_of_skull_ORDERED anteriorly subvertical inclined_about_120 _posteriorlyned_about_120 _backwards_

inclined_about_150 $0^{\circ} \_$posteriorly;

\{56 Cranio-mandibular_articulation,_position_relative_to_orbit_ORDERED _posteri-

or_to_posterior_margin_of_orbit under_center_of_orbit_under_anterior_mar-

gin_of_the_orbit anterior_to_anterior_margin_of_orbit;

$\{57$ Helical_jaw_joint absent_present_;

$\{58$ Frontal,_anterior_portion_rugose absent present;

$\{59$ Frontal,_ossified_crest absent present;

$\{60$ Frontal,_ossified_crest,_position_ORDERED confined_to_posterior_end_of_skull starting_above_orbit starting_on_posterior_half_of_nasoantorbital_fenestra;

\{61 Frontal,_ossified_crest,_shape_low,_blunt short._spike-like,_dorsally_deflected

spikelike,_directed_posteriorly narrow,_broad,_directed_posteriorly

low,_broad_base,_fans-shaped high,_broad_base,_crown-shaped

high,_broad_base,_casqued-shaped high,_broad,_directed_posteriorly,_at_least_dou-

bling_shight_of_skull_above_orbit absent;

$\{62$ Parietal,_ossified_crest absent present;

$\{63$ Parietal,_ossified_crest,_shape_blunt

constituting_the_base_of_the_posterior_portion_of_the_cranial_crest

expanded,_with_rounded_margin;

\{64 Posterior_region_of_the_skull_rounded_with_the_squamosal_displaced_ventrally absent_present_;

\{65 Supraoccipital does_not_extend_backwards_extends_backwards_;

\{66 Supraoccipital,_foramen_absent_present_;

$\{67$ Paroccipital_processes,_expanded_distal_ends_absent_present_;

$\{68$ Foraminae_piercing_the_anterior_portion_of_the_palate,_numerous absent pres-

ent;

$\{69$ Palatal_occlusal_surface_ORDERED smooth discrete_palatal_ridge,_taper-

ing_anteriorly_strong_palatal_ridge,_tapering_anteriorly strong_palatal_ridge,_con-

fined_to_the_posterior_portion_of_the_palate;

$\{70$ Palate,_dorsal_deflection absent present;

$\{71$ Pal-

ate,_slight_expansion_close_to_the_anterior_margin_of_the_nasoantorbital_(or_naris _+_antorbital)_fenestra absent present;

$\{72$ Maxilla_and_internal_naris,_contact_absent_present_;

$\{73$ Palatines,_shape_broad thin_bars;

\{74 Basisphenoid_body,_length_shorter_than_wide longer_than_wide;

$\{75$ Mandibular_rostral_end, extension_of_the_contact_surface_of_opposing_den-

taries_ORDERĒD short,_limited_to_the_tip short,_extended_posteriorly_-

less_than_30\%_of_mandible_length long,_up_to_55\%_the_mandible_length

long,_extended_over_55\%_of_mandible_length;

$\{76$ Mandibular_rostral_end,_odontoid_process absent present;

\{77 Mandibular_rostral_end,_opposing_dentaries_unfused fused; 
\{78 Mandibular_rostral_end,_shape_rounded pointed sharp_tip;

$\{79$ Dentary,_dorsal_mar-

gin,_distinct_posterior_eminence_close_to_the_separation_of_mandibular_rami

absent present;

\{80 Tip_of_the_dentary_projected_anteriorly absent_present_;

\{81 Dentary_ossified_sagittal_crest absent present;

\{82 Dentary_ossified_sagittal_crest,_position_confined_to_the_anteri-

or_third_of_the lower_jaw extinding_close_to_the_middle_portion_of the llower_jaw;

$\{83$ Dentary_ossified_sagittal_crest,_shape_shallow blade-like deep,_broäd_in_later-

al_view elongated_ridge;

$\{84$ Dentary,_posteroventral_fossa absent present;

\{85 Teeth,_position_and_presence present,_evenly_distributed_along_the_jaws_

teeth_absent_from_the_anterior_portion_of_the_jaws_confined_to_the_anteri-

or_part_of_the_jaws jaw_toothless;

\{86 Teeth,_confined_to_the_anterior_part_of_the_jaws confined_to_the_anteri-

or_half_of_the_jaws confined_to_the_anterior_quarter_of_the_jaws;

$\{8 \overline{7}$ Maxillary_teeth,_largest_positioned_posteriorly_absent_present_;

$\{88$ Teeth,_shape_variation isodont heterodont;

\{89 Teeth,_anterior,_height_versus_width_proportion more_than_twice_their_width

less_than_twice_their_width;

$\{90$ Teeth,_anterior,_marked_variation_in_size absent present;

\{91 Teeth,_upper_-

jaw,_variation_in_the_size_of_the_anterior_teeth_with_the_5th_and_6th_smaller_tha

n_the_4th absent_present_;

$\{92$ Teeth,_base_broad_and_oval absent_present_;

\{93 Teeth,_serrated present absent;

\{94 Teeth,_cingulum absent present;

\{95 Teeth,_peg-like_(cone-shaped) absent_present;

\{96 Teeth,_small_needle-shaped absent present;

$\{97$ Teeth,_labiolingually_compressed_crowns absent present;

$\{98$ Teeth,_labiolingually_compressed_crowns,_compression_ORDERED not_com-

pressed slightly_compressed strongly_compressed;

\{99 Teeth,_sharp_carinae absent present;

$\{100$ Teeth,_elongated absent present;

\{101 Teeth,_striated absent present;

\{102 Teeth,_curvature_of_the_toothline absent present;

\{103 Teeth,_first_pair_above_second_pair absent present;

$\{104$ Alveoli,_lateral_platform absent present;

\{105 Atlas_and_axis unfused_fused_;

$\{106$ Cervical_vertebrae,_postexapophyses_absent_present_;

$\{107$ Mid-cervical_vertebrae,_centrum,_lateral_foramen_absent_present_;

$\{108$ Mid-cervical_vertebrae,_length_ORDERED short,_sub-equal_in_length_lon-

ger_than_wide,_with_length_less_than_3_times_width elon-

gated,_with_length_more_than_3_times_width extremely_elongate;

$\{109$ Mid-cervical_vertebrae,_ribs present_absent_;

$\{110$ Mid-cervical_vertebrae,_neural_spines,_height_ORDERED tall low extreme-

ly_reduced_or_absent;

$\{111$ Mid-cervical_vertebrae,_neural_spines,_shape_blade-shaped spike-shaped_ ridge;

$\{112$ Notarium absent_present_;

\{113 Caudal_vertebrae,_quantity_more_than_15_15_or_less_;

\{114 Caudal_vertebrae,_zygapophyses_forming_rod-like_ossified_processes_absent present;

\{115 Proximal_caudal_vertebrae_centrum,_centrum_shape_single douplex; 
\{116 Scapula,_length_relative_to_coracoid_length_ORDERED subequal_or_longer_than_coracoid_scapula_shorter_than_coracoid_(1_>_sca/cor_>_0.80)_substantially_shorter_than_coracoid_(sca/cor_<_0.80);

$\{117$ Scapula,_proximal_end_elongated_sub-oval_;

$\{118$ Scapula,_shape_elongated_stout,_with_constructed_shaft_;

\{119 Coracoid,_proximal_end,_shape flattened oval;

$\{120$ Coracoid,_sternal_articulation_ORDERED no_developed_articulation articula-

tion_surface_straight_or_slightly_concave articulation_surface_strongly_concave;

\{121 Coracoid,_sternal_articulation,_posterior_expansion_absent present;

\{122 Coracoid,_ventral_margin,_deep_flange absent present;

\{123 Coracoid,_broad_tubercle_on_ventroposterior_margin absent present;

\{124 Cristospine,_shape_absent_shallow_and_elongated_deep_and_short;

$\{125$ Humerus,_proportional_length_relative_to_the_metacarpal_IV_(hu/mclV)_OR-

DERED hu/mclV_>_2.50_1.50_< hu/mclV_<_2.50_0.40_< hu/mclV_<_1.50 hu/

mclV_<_0.40;

$\{126$ Humerus,_proportional_length_relative_to_the_femur_(hu/fe)_ORDERED hu/ $\mathrm{fe}<0.80 \_1.4 \_>\mathrm{hu} / \mathrm{fe}>\quad 0.80 \_\mathrm{hu} / \mathrm{fe}>>1.40$;

$\{127$ Humerus_plus_ulna,_proportional_lengths_relative_to_the_femur_plus_tibia_(hu+ul/fe+ti)_ORDERED humerus_plus_ulna_about_0.80\%_or_less_of_fe-

mur_plus_tibia_length_(hu+ul/fe+ti_<_0.80)_

humerus_plus_ulna_larger_than_0.80\%_of_femur_plus_tibia_length_(hu+ul/

fe+ti_>_0.80)_;

$\{128$ Humerus,_proxi-

mal_end,_small_foramen_on_dorsal_surface_distal_to_proximal_articulation absent

present;

\{129 Humerus,_proximal_end,_foramen_on_ventral_surface_close_to_proximal_margin_absent_present_;

$\{130$ Humerus,_deltopectoral_crest,_shape_reduced,_positioned_close_to_the_humerus_shaft enlarged,_proximally_placed,_with_almost_straight_proximal_margin_ enlarged,_hatchet_shaped,_proximally_placed enlarged,_hatched_shaped,_positioned_further_down_the_humerus_shaft enlarged,_warped long,_proximally_placed,_curving_ventrally;

\{131 Humerus,_medial_(=_ulnar)_crest_reduced_directed_posteriorly_massive,_with_a_developed_proximal_ridge;

\{132 Humerus,_distal_articulation,_shape_oval_or_D-shaped_subtriangular_;

\{133 Humerus,_between_distal_condyles,_pneumatic_foramen absent present;

$\{134$ Ulna_and_radius,_diameter_at_midshaft_ORDERED subequal_diameter_of_radius_about_half_that_of_ulna diameter_of_radius_less_than_half_that_of_ulna;

\{135 Proximal_syncarpal,_large_posterodistal_process absent present;

\{136 Proximal_syncarpal,_shape_(proximal_view) quadrangular_or_irregular pentagonal;

$\{137$ Distal_syncarpals,_shape_(distal_view)_irregular form_rectangular_unit_form_triangular_unit;

\{138 Pteroid_ORDERED absent_shorter_than_half_the_length_of_the_ulna_longer_that_half_the_length_of_the_ulna;

$\{13 \overline{9}$ Pteroid,_proximal_articulation,_expanded_in_right_angle_with_shaft absent present;

\{140 Metacarpals_I_-_III,_relation_with_carpus_ORDERED articulating_with_carpus_ metacarpal_I_articulates_with_carpus,_metacarpals_II_and_III_reduced_not_articulating_with_carpus;

$\{141$ Manual_digit_IV_first_phalanx,_proportional_length_relative_to_metacarpal_IV_(ph1 1 d $4 / \mathrm{mcIV})$ _ORDERED both_small_and_reduced_ph1d $4 / \mathrm{mclV}>4.0$

$4.0>\mathrm{ph} 1 \mathrm{~d} 4 / \mathrm{mclV}>2.0$ '2.0>_ph1d4/mclV $>1.0$ ' ' $\mathrm{ph} 1 \mathrm{~d} 4 / \mathrm{mclV}<\_1.0$ '; 
\{142 Manual_digit_IV_first_phalanx,_proportional_length_relative_to_tibiotarsus_(ph1d4/ti)_ORDERED ph1d4_reduced_ph1d4_elongated_and_less_than_twice_the_length_of_ti_(ph1d4/ti_smaller_than_2.00)

ph1d4_elongated_about_or_longer_than_twice_the_length_of_ti_(ph1d4/ti_subequal/ larger_than_2.00);

$\{143$ Manual_digit_IV_second_phalanx,_proportional_length_relative_to_first_phalanx_(ph2d4/ph1d4)_ORDERED both_short_or_absent_ elongated_with_second_phalanx_about_the_same_size_or_longer_than_first_(ph2d4 /ph1d4_larger_than_1.00)_elongated_with_second_phalanx_up_to_30\%_shorter_than_first_(ph2d4/ph1d4_between_0.70_-_1.00) elongated_with_second_phalanx_more_than_30\%_shorter_than_first_(ph2d4/ph1d4_smaller_than_0.70);

\{144 Manual_digit_IV_third_phalanx,_proportional_length_relative_to_first_phalanx_(ph3d4/ph1d4)_ORDERED both_short_or_absent ph3d4_about_the_same_length_or_larger_than_ph1d4_ph3d4_shorter_than_ph1d4; $\{145$

Proportional_length_of_the_forth_phalanx_of_manual_digit_IV_relative_to_the_first_p halanx_of_manual_digit_IV_(ph4d4/ph1d4)_ORDERED both_short_or_absent both_elongated,_with_the_forth_phalanx_longer_than_the_first_(ph4/d4>1.00) both_elongated,_with_the_forth_phalanx_the_same_length_or_shorter,_but_longer_than_35\%_ the_length_of_the_first both_elongated,_with_the_forth_phalanx_less_than_35\% the length_of the first;

$\{146$ Femur,_length_relative_to_metacarpal_IV_length_(fe/mclV)_ORDERED femur_at_least_twice_the_metacarpal_IV_length_(fe_? mclV_>_2.00) femur_longer_but_less_than_twice_the_length_of_metacarpal_IV_(1.00_<_fe/mclV_<_2.00) femur_about_the_same_length_or_shorter_than_metacarpal_IV_(fe/mclV_<_1.00); $\{147$ Metatarsal_III,_proportional_length_relative_to_tibia_length_more_than_30\%_of_tibia_length_less_than_30\%_of_tibia_length_; $\{148$ Pedal_digit_V,_number_of_phalanges_ORDERED with_four_phalanges_ with_2_phalanges_with_1_or_no_phalanx_(extremely_reduced); $\{149$ Pes,_second_phalanx_of_digit_V,_shape_reduced_or_absent_elongated,_straight_elongated,_curved èlongated,_very_curved_(boomerang_shape); ; ccode $+162246525556607598108110116120$ $125126127134140141142143144145146148^{*}$;

proc /;

comments 0

S1.3. TNT Data Matrix for Postcranial Characters-Only Phylogenetic Analysis of Hone et al., (2020)

xread

4544

Ornithosuchus_woodwardi 000000000000000000000000000000000000000000000

Herrerasaurus_ischigualastensis 000000000000000000000000000000000000000000020

Scleromochlus_taylori ???00??0000??0?000???00??0???0???00?0000000??

Anurognathus_ammoni ???0???01000?0???0??0110?100000??1001122?0011

Rhamphorhynchus_muensteri

$00000000010000010001111002000100 ? 100122221012$

Darwinopterus_linglongtaensis

???10??001?0?00?000?1110?100?10??100311111022 
Darwinopterus_robustodens

???1???001?0?00??0??111??100?10??10031111102?

Pterodactylus_antiquus

$0002110010000001000121100500 ? 100 ? 100312222020$

Dsungaripterus_weii

$1111100110 ? 000 ? ? ? 0 ? 2210 ? ? 5 ? 001001 ? ? 13122 ? 2120$

Noripterus_parvus

?11??0??????????????????????0?001????????????

Keresdrakon_vilsoni

?111?00?????00020011?0?01520?1???????????????

Tupuxuara_leonardii

11111001???00002001?2100152011001?01313??2???

Caupedactylus_ybaka

???????????00002001????015200????????????????

Caiuajara_dobruski

?1111000?0?00002?01?21?11520?1??120??????????

Tapejara_wellnhoferi

?1111000?0?00002001?210115200100120?31???2120

Sinopterus_dongi

?1?11000???0000200??211?152??100?20?3122321??

Huaxiapterus_corollatus

?1?11??0???000???0??211??5??????????3132321??

Huaxiapterus_benxiensis

?1?11??0????????????2????????????20?3122?2120

Eopteranodon_lii

????????????????????21???5??????????3?22?2???

Chaoyangopterus_zhangi

?102110????000???10?200??????100?20?3132?21?0

Shenzhoupterus_chaoyangensis

?1021??????0?0???1??200??5???100????3122321??

Jidapterus_edentus

?1?2110??????0???1??200??5?0?100????312232120

Azhdarcho_lancicollis

11031221???????????????015?0?????????????????

Quetzalcoatlus_sp.

11031221?0?00002010?20?0152001001???4132?2?20

Zhejiangopterus_linhaiensis

1??31221?0?000???10?200??5???100?20?413??2???

Nyctosaurus_gracilis

$11 ? 110111000 ? 00100013110130 ? 011122123222 ? 20 ? ?$

Muzquizopteryx_coahuilensis

???11011????1????????11??30??111121???????1??

Pteranodon_longiceps

111110111011101200012110141111112202322232020

Tethydraco_regalis

???????????????????????014111????????????????

Ikrandraco_avatar

1111101?????????????2????41??2112201??2??????

Hamipterus_tianshanensis

1111101????1?????00????1041002?12?0??????????

Tropeognathus_mesembrinus

?1111011????11???002???????10211?????????????

AMNH_22555

1111101?1??21112100????1041102112??1????????? 
Anhanguera_piscator 1111101?1012111210022111041102112??1?????2120 Liaoningopterus_gui 111?1????????????????????????????????????????

Guidraco_venator

?1111????????????????????????????????????????

Mimodactylus_libanensis_gen._et_sp._nov. ???????0?00111?1?002211??4???211?2013222221?? Haopterus_gracilis ???11??0???111?1?0?22???04???21?????3?22???20 Hongshanopterus_lacustris 1?11101?????????????????????????????????????? Istiodactylus_latidens ?111?011???111020002?1?10411?2112???????????? Istiodactylus_sinensis 1??11??1???1?1???0??21???4???211???13122??1?? Nurhachius_ignaciobritoi ??111011???1?10200?2211?041??2112??1312??21?? Nurhachius luei ?1?110???????????????????????????????????????

Luchibang_wuke ?1?11????????102000?201??40??1??????212222120 ;

cnames

$\{0$ Atlas_and_axis unfused_fused_;

$\{1$ Cervical_vertebrae,_postexapophyses_absent_present_;

\{2 Mid-cervical_vertebrae,_centrum,_lateral_foramen_absent_present_;

\{3 Mid-cervical_vertebrae,_length_ORDERED short,_sub-equal_in_length_longer_than_wide,_with_length_less_than_3_times_width elongated,_with_length_more_than_3_times_width extremely_elongate;

$\{4$ Mid-cervical_vertebrae,_ribs present_absent_;

\{5 Mid-cervical_vertebrae,_neural_spines,_height_ORDERED tall low extremely_reduced_or_absent;

$\{6$ Mid-cervical_vertebrae,_neural_spines,_shape_blade-shaped spike-shaped_ ridge;

$\{7$ Notarium absent_present_;

\{8 Caudal_vertebrae,_quantity_more_than_15_15_or_less_;

\{9 Caudal_vertebrae,_zygapophyses_forming_rod-like_ossified_processes_absent present;

\{10 Proximal_caudal_vertebrae_centrum,_centrum_shape_single douplex;

\{11 Scapula,_length_relative_to_coracoid_length_ORDERED subequal_or_lon-

ger_than_coracoid_scapula_shorter_than_coracoid_(1_>_sca/cor_>_0.80)_substan-

tially_shorter_than_coracoid_(sca/cor_<_0.80);

\{12 Scapula,_proximal_end_elongated_sub-oval_;

$\{13$ Scapula,_shape_elongated_stout,_with_constructed_shaft_;

\{14 Coracoid,_proximal_end,_shape flattened oval;

$\{15$ Coracoid,_sternal_articulation_ORDERED no_developed_articulation articulation_surface_straight_or_slightly_concave articulation_surface_strongly_concave; $\{16$ Coracoid,_sternal_articulation,_posterior_expansion_absent present;

$\{17$ Coracoid,_ventral_margin,_deep_flange absent present;

$\{18$ Coracoid,_broad_tubercle_on_ventroposterior_margin absent present;

$\{19$ Cristospine,_shape_absent_shallow_and_elongated_deep_and_short; 
$\{20$ Humerus,_proportional_length_relative_to_the_metacarpal_IV_(hu/mclV)_ORDERED hu/mclV_>2 2.50_1.50_< hu/mclV_<_2.50_0.40_< hu/mclV_<_1.50 hu/ mclV_<_0.40;

$\{21$ Humerus,_proportional_length_relative_to_the_femur_(hu/fe)_ORDERED hu/ $\mathrm{fe}<0.80 \_1.4 \_>\mathrm{hu} / \mathrm{fe}>\quad 0.80 \_\mathrm{hu} / \mathrm{fe}>>1.40$;

$\{22$ Humerus_plus_ulna,_proportional_lengths_relative_to_the_femur_plus_tibia_(hu+ul/fe+ti)_ORDERED humerus_plus_ulna_about_0.80\%_or_less_of_femur_plus_tibia_length_(hu+ul/fe+ti_<_0.80)

humerus_plus_ulna_larger_than_0.80\%_of_femur_plus_tibia_length_(hu+ul/ fe+ti_>_0.80)_;

$\{23$ Humerus, proxi-

mal_end,_small_foramen_on_dorsal_surface_distal_to_proximal_articulation absent present;

\{24 Humerus,_proximal_end,_foramen_on_ventral_surface_close_to_proximal_margin_absent_present_;

$\{25$ Humerus,_deltopectoral_crest,_shape_reduced,_positioned_close_to_the_humerus_shaft enlarged,_proximally_placed,_with_almost_straight_proximal_margin_ enlarged,_hatchet_shaped,_proximally_placed enlarged,_hatched_shaped,_positioned_further_down_the_humerus_shaft enlarged,_warped long,_proximally_placed,_curving_ventrally;

$\{26$ Humerus,_medial_(=_ulnar)_crest_reduced_directed_posteriorly_massive,_with_a_developed_proximal_ridge;

$\{27$ Humerus,_distal_articulation,_shape_oval_or_D-shaped_subtriangular_;

$\{28$ Humerus,_between_distal_condyles,_pneumatic_foramen absent present;

$\{29$ Ulna_and_radius,_diameter_at_midshaft_ORDERED subequal_diameter_of_radius_about_half_that_of_ulna diameter_of_radius_less_than_half_that_of_ulna;

$\{30$ Proximal_syncarpal,_large_posterodistal_process absent present;

\{31 Proximal_syncarpal,_shape_(proximal_view) quadrangular_or_irregular pentagonal;

\{32 Distal_syncarpals,_shape_(distal_view)_irregular form_rectangular_unit_form_triangular_unit;

\{33 Pteroid_absent_shorter_than_half_the_length_of_the_ulna_lon-

ger_that_half_the_length_of_the_ulna;

$\{34$ Pteroid,_proximal_articulation,_expanded_in_right_angle_with_shaft absent present;

\{35 Metacarpals_I_-_III,_relation_with_carpus_ORDERED articulating_with_carpus_ metacarpal_I_articulates_with_carpus,_metacarpals_II_and_III_reduced_not_articulating_with_carpus;

\{36 Manual_digit_IV_first_phalanx,_proportional_length_relative_to_metacar-

pal_IV_(ph1d4/mcIV)_ORDERED both_small_and_reduced_ph $\overline{1} \mathrm{~d} 4 / \mathrm{mclV}>4.0$

$4.0>\mathrm{ph} 1 \mathrm{~d} 4 / \mathrm{mclV}>2.0$ '2.0>_ph1d4/mclV $>1.0^{\prime}$ ' $\mathrm{ph} 1 \mathrm{~d} 4 / \mathrm{mclV}<-1.0^{\prime}$;

$\{37$ Manual_digit_IV_first_phalanx,_proportional_length_relative_to_tibiotar-

sus_(ph1d4/ti)_ORDERED ph1d4_reduced_ph1d4_elongated_and_-

less_than_twice_the_length_of_ti_(ph1d4/ti_smaller_than_2.00)

ph1d4_elongated_about_or_longer_than_twice_the_length_of_ti_(ph1d4/ti_subequal/ larger_than_2.00);

\{38 Manual_digit_IV_second_phalanx,_proportional_length_relative_to_first_phalanx_(ph2d $4 / \mathrm{ph} 1 \mathrm{~d} 4)$ _ORDERED both_short_or_absent_

elongated_with_second_phalanx_about_the_same_size_or_longer_than_first_(ph2d4 /ph1d4_larger_than_1.00)_elongated_with_second_phalanx_up_to_30\%_short-

er_than_first_(ph2d $4 / \mathrm{ph} 1 \mathrm{~d} 4$ _between_0.70_-_1.00) elongated_with_second_phalanx_more_than_30\%_shorter_than_first_(ph2d4/ph1d4_smaller_than_0.70); 
\{39 Manual_digit_IV_third_phalanx,_proportional_length_relative_to_first_phalanx_(ph3d $4 / \mathrm{ph} 1 \mathrm{~d} 4)$ _ORDERED both_short_or_absent_ ph3d4_about_the_same_length_or_larger_than_ph1d4_ph3d4_shorter_than_ph1d4; $\{40$

Proportional_length_of_the_forth_phalanx_of_manual_digit_IV_relative_to_the_first_p halanx_of_manual_digit_IV_(ph4d4/ph1d4)_ORDERED both_short_or_absent both_elongated,_with_the_forth_phalanx_longer_than_the_first_(ph $4 / \mathrm{d} 4 \overline{4}>1.00)$ both_elongated,_with_the_forth_phalanx_the_same_length_or_shorter,_but_longer_than_35\%_ the length_of_the first both_elongated,_with_the_forth_phalanx_-

less_than_35\%_the_length_of_the_first;

$\{41$ Femur,_length_relative_to_metacarpal_IV_length_(fe/mcIV)_ORDERED

femur_at_least_twice_the_metacarpal_IV_length_(fe_? mclV_>_2.00) femur_longer_but_less_than_twice_the_length_of_metacarpal_IV_(1.00_<_fe/mclV_<_2.00) femur_about_the_same_length_or_shorter_than_metacarpal_IV_(fe/mclV_<_1.00); \{42 Metatarsal_III,_proportional_length_relative_to_tibia_length_ more_than_30\%_of_tibia_length_less_than_30\%_of_tibia_length_; \{43 Pedal_digit_V̄,_number_of_phalanges_oRDERED with_four_phalanges_ with_2_phalanges_with_1_or_no_phalanx_(extremely_reduced); $\{44$ Pes,_second_phalanx_of_digit_V,_shape_reduced_or_absent_elongated,_straight_elongated,_curved elongated,_very_curved_(boomerang_shape); ; ccode + 3511152021293536373839404143

*;

proc /;

comments 0

\section{S2. Consistency of the specimen}

The specimen is unusual for an istiodactylid pterosaur in showing postcranial features more consistent with members of other clades of pterodactyloid pterosaur that are common in the Jehol beds of China. Given that previous specimens are known to have been modified by fossil dealers it has been suggested that this specimen may represent a chimera with an istiodactylid head placed onto an azhdarchid postcranium. Evidence for this hypothesis is assessed below.

In favour of the idea that ELDM 1000 may be a chimera is that the fact that the colour / texture of the cranial elements are not entirely consistent with that of the postcranium, and the unusual distribution of characters between the head and body. With regards to the first point, such changes are also noted in other Jehol-type specimens with some parts often being preserved rather differently to others. For example the head of a specimen of Microraptor (IVPP $17972 \mathrm{~A}$ ) is rather different in colour and preservation to the rest of the specimen and parts of Longchengpterus are much darker than others. While this may in part be due to the manner of preparation of the material, it does not mean these are chimeras. Similarly, although such character changes are discrepancies between two anatomical modules of an animal are very rare, at least one pterosaur group, the Wukongopteridae show just such a distribution of features. Certainly both lines of evidence are important, but neither is definitive.

A number of pieces of data support the idea that the specimen is genuine. The skull of the animal is approximately the correct size for an istiodactylid pterosaur being c. $15 \%$ of the wingspan of the animal (total length, allowing of the missing portion) compared to c. $18 \%$ for Istiodactylus (based on figure 15.5 Witton, 2013, p.149) and also appears to belong to a juvenile animal given the disarticulation of the posterior part of the cranium. Finding a consistently sized and aged cranium (and indeed is at least very similar if not identical to the postcranium in colour and texture) from a second specimen would be very difficult given the variation seen in preservation of Jehol fossils, supporting the idea that the skull does belong with the postcranium.

If the skull is from a separate animal, then either the bones of this have been incised into a large slab of matrix containing the postcranium, or matrix containing the skull has been added to 
the main piece. In either case, the spaces between the skull and postcranium are the critical zones and if there have been alterations to the material it should show here. The matrix as a whole is variable, as is common for such specimens, especially when this size, and thus is consider equivocal in this context. However, despite the variation and inevitable crack and breaks, the surface as a whole is generally consistent with itself, and certainly there is nothing distinctive about the region of matrix that include the cranium. Some cracks and breaks have had minor repairs but there is no indication of major repairs or addition of glues, consolidants or other artificial work to any part of the specimen.

Several simple tests were carried out on the material to check for any evidence that the cranium, or the matrix containing this part, were added to the rest of the material. First, the edge of the maxilla where it terminates off the end of the slab was examined visually, and then a small amount of preparation work was carried out at this location. Neither the examination or removal of matrix suggested that there were any breaks or cracks in the matrix that might indicate that the maxilla had been cut into existing matrix.

There is some small amount of glue on the tip of the maxilla (apparently to consolidate the broken tip) but removal of some of this showed that it did not extend far into the matrix, and there were no issues detected outside of the glued area. Additionally, visual examination of the edge of the specimen around the whole upper left quadrant showed no unusual patterns or breaks or inconsistencies between layers of the matrix that would indicate modification to the matrix. The slab is only around $10 \mathrm{~mm}$ thick and as a result somewhat fragile, however the edges could be shifted to expose the underside of the main slab and this was also examined around the edge of the upper left quadrant, and again, no issues were detected. There is a pair of large cracks in the specimen though the skull and the cervicals, and also a number of holes across the specimen. The latter are consistent with some surface cracking and damage to the matrix (this is common in Jehol material) and these appear across the specimen, even areas considered quite genuine (e.g. near the right wrist) and thus should not impinge on the validity of the cranium where some similar holes exist, though not directly next to the bone where this might be expected if there has been alterations to the specimen. In the cases of the cracks, no inconsisencies can be found at their margins or along the edges and both are similar to one another in how they affect the matrix and bones. The conclusion here is that the maxilla is naturally within this part of the matrix and the bones have not been cut into an existing piece of matrix.

Similarly, examination and preparation in three distinct locations (between the scapula and mandible, between the right ramus of the mandible and $6^{\text {th }}$ cervical, and finally in the space between the left ramus of the mandible, maxilla and seventh cervical vertebra) by DWEH and an independent observer revealed no evidence of tampering. There was no undercutting of the matrix, no glue or consolidants, and the matrix was entirely consistent in these areas and reached the bone naturally. Between the mandible, maxilla and $7^{\text {th }}$ cervical, the matrix was removed and revealed bone-to-bone contact between each element.

Preparation of these areas and that at the tip of the maxilla was then compared to other parts of the matrix. Several points across the matrix were chosen and subjected to simple scrapes similar to those carried out above to dig into the matrix below the surface layer. These areas were chosen as locations very unlikely to have been altered during any work to add the skull to the postcranium and thus most likely to be correct representatives of the matrix. Again, no inconsistencies were found. Preparation of one of the areas that did have glue on it, showed this to be very difference in appearance to the nature of the matrix prepared in key areas noted above.

Finally, there was a careful visual check (with the naked eye, and both 10X and 30X lenses) of the major elements of the skull and postcranium in places where they touch show that they are continuous. That is, the bones meld into one another where they meet. There are continuous parts of the mandible with the right scapula, with the mandible and maxilla and a cervical (as noted above), and finally with the maxilla and a cervical. This is similar, if not identical to, the joins also seen between multiple cervicals and other postcranial elements. Therefore the mandible, maxilla and postcranium are continuous with one another in what is effectively therefore an unbroken series of elements. There are also some minor cracks on the specimen that appear to run through the bones and matrix quite naturally and link together disparate parts of the specimen. If the skull and / or surrounding matrix had been added to this thin slab, there should be a break somewhere between the two parts and any force sufficient to crack the material should be 
directed here, and not pass across the break and continue with a natural and normal break across numerous elements, again suggesting these are genuinely and normally connected.

Collectively, these provide very strong evidence that the specimen is genuine and unaltered. Although the skull is an imperfect match, it is largely consistent with the postcranium in size, ontogenetic status, colour and texture. There is no indication that the maxilla (and by extension the skull) has been incised into the matrix, nor any indication that one piece of matrix has been added to another. Areas where modifications to either the bones or matrix would be expected if the head did not match the rest of the specimen also show no indications of changes and the matrix appears to be entirely natural around the bones in numerous parts of the specimen and the surface, edge and underside of the slab appeared consistent. Most critically, as far as can be determined there is a continuum of the bony parts of skull and postcranium with bones meeting and even melding together. This would seem difficult if not absolutely impossible to do convincingly. Preparation in key areas that might expose work done and carefully hidden did not reveal inconsistencies or errors, but instead additional connections between elements.

We cannot absolutely confirm that the specimen is genuine since it was not collected or prepared under our supervision and understandably suspicion will linger, since there are no absolute tests to determine is a given specimen, or part of it, is genuine. All of the evidence must be assessed and an appropriate conclusion reached, and while additional work (e.g. UV light work, further preparation) would be welcomed, we feel that the data is consistent and the specimen should provisionally be considered genuine. However, although some parts of the anatomical disjunct are unexpected and strong, we have been unable to detect any evidence of tampering on any part of the specimen, and indeed have found great consistency especially with the contact between elements.

\section{REFERENCE}

Witton MP, 2013. Pterosaurs: natural history, evolution, anatomy. Princeton University Press.

\section{S3. Humeral and Hindlimb Length Data}

Length data (in mm) was retained from Elgin (2014). All Pterodactyloidea data was used with the exception of several indeterminate taxa and excluding some of the smallest specimens of archaeopterodactyloids that represent small juveniles. The measurements for Nurhachius ignaciobritoi were added, taken from Wang et al., (2005).

\begin{tabular}{llcc}
\hline & \multicolumn{1}{c}{ Clade/Grade } & hu & HL \\
\hline Luchibang wuke & Istiodactylid & 110 & 355 \\
Nurhachius ignaciobritoi & Istiodactylid & 121 & 262 \\
Boreopterus cuiae & Pteranodontoidea & 79 & 164 \\
Arthurdactylus conandoylei & Pteranodontoidea & 230 & 424 \\
Coloborhynchus robustus & Pteranodontoidea & 290 & 615 \\
Coloborhynchus spielbergi & Pteranodontoidea & 290 & 629.6 \\
Pteranodon sp. & Pteranodontidae & 134 & 354 \\
Pteranodon sp. & Pteranodontidae & 247 & 565 \\
Pteranodon sp. & Pteranodontidae & 191 & 446.5 \\
Pteranodon sp. & Pteranodontidae & 168 & 416 \\
Pteranodon sp. & Pteranodontidae & 171 & 385.5 \\
Muzquizopteryx coahuilensis & Pteranodontidae & 80.5 & 187 \\
Nyctosaurus 'bonneri' & Pteranodontidae & 97 & 204 \\
Nyctosaurus gracilis & Pteranodontidae & 87 & 214 \\
Nyctosaurus gracilis & Pteranodontidae & 87 & 214 \\
Nyctosaurus sp. & Pteranodontidae & 72.3 & 155.5 \\
Cycnorhamphus suevicus & Archaeopterodactyloidea & 65.5 & 199
\end{tabular}




\begin{tabular}{|c|c|c|c|}
\hline Pterodactylus antiquus & Archaeopterodactyloidea & 31.5 & 83 \\
\hline Pterodactylus antiquus & Archaeopterodactyloidea & 43.7 & 104 \\
\hline Pterodactylus antiquus & Archaeopterodactyloidea & 31.7 & 76 \\
\hline Pterodactylus antiquus & Archaeopterodactyloidea & 32.5 & 77 \\
\hline Pterodactylus antiquus & Archaeopterodactyloidea & 41 & 98.5 \\
\hline Beipiaopterus chenianus & Archaeopterodactyloidea & 68 & 144 \\
\hline Ctenochasma gracilis & Archaeopterodactyloidea & 38.5 & 90 \\
\hline Ctenochasma gracilis & Archaeopterodactyloidea & 17 & 35.2 \\
\hline Ctenochasma gracilis & Archaeopterodactyloidea & 16.9 & 36.5 \\
\hline Ctenochasma gracilis & Archaeopterodactyloidea & 19.2 & 37 \\
\hline Ctenochasma gracilis & Archaeopterodactyloidea & 19.5 & 38.3 \\
\hline Gnathosaurus subulatus & Archaeopterodactyloidea & 23 & 60 \\
\hline Gnathosaurus subulatus & Archaeopterodactyloidea & 23 & 57 \\
\hline Gnathosaurus subulatus & Archaeopterodactyloidea & 25 & 69.5 \\
\hline Gnathosaurus subulatus & Archaeopterodactyloidea & 26 & 74 \\
\hline Gnathosaurus subulatus & Archaeopterodactyloidea & 28 & 82 \\
\hline "Pterodactylus" longicollum & Archaeopterodactyloidea & 78 & 248 \\
\hline Pterodaustro guinazui & Archaeopterodactyloidea & 80 & 150 \\
\hline Germanodactylus cristatus & Archaeopterodactyloidea & 56 & 56.5 \\
\hline Germanodactylus rhamphastinus & Archaeopterodactyloidea & 49.5 & 130 \\
\hline Germanodactylus rhamphastinus & Archaeopterodactyloidea & 60 & 159 \\
\hline Huaxiapterus corollatus & Azhdarchoidea & 79.7 & 247.5 \\
\hline Huaxiapterus jii & Azhdarchoidea & 79 & 241 \\
\hline Sinopterus dongi & Azhdarchoidea & 58.5 & 178 \\
\hline Sinopterus gui & Azhdarchoidea & 35.5 & 96.1 \\
\hline Chaoyangopterus zhangi & Azhdarchoidea & 93 & 338 \\
\hline Eoazhdarcho liaoxiensis & Azhdarchoidea & 90 & 254 \\
\hline Shenzhoupterus chaoyangensis & Azhdarchoidea & 66 & 241 \\
\hline Zhejiangopterus linhaiensis & Azhdarchoidea & 137 & 487 \\
\hline
\end{tabular}

\section{REFERENCES}

Elgin R. A. 2014. Palaeobiology, Morphology, and flight characteristics of pterodactyloid pterosaurs. PhD Thesis, University of Heidelberg. 273pp.

Wang, X.-L., Kellner, A.W.A., Zhou, Z.-H., Campos, D.A., 2005. Pterosaur diversity and faunal turnover in Cretaceous terrestrial ecosystems in China. Nature 437, 875-879. 


\section{S4. Supporting figures}

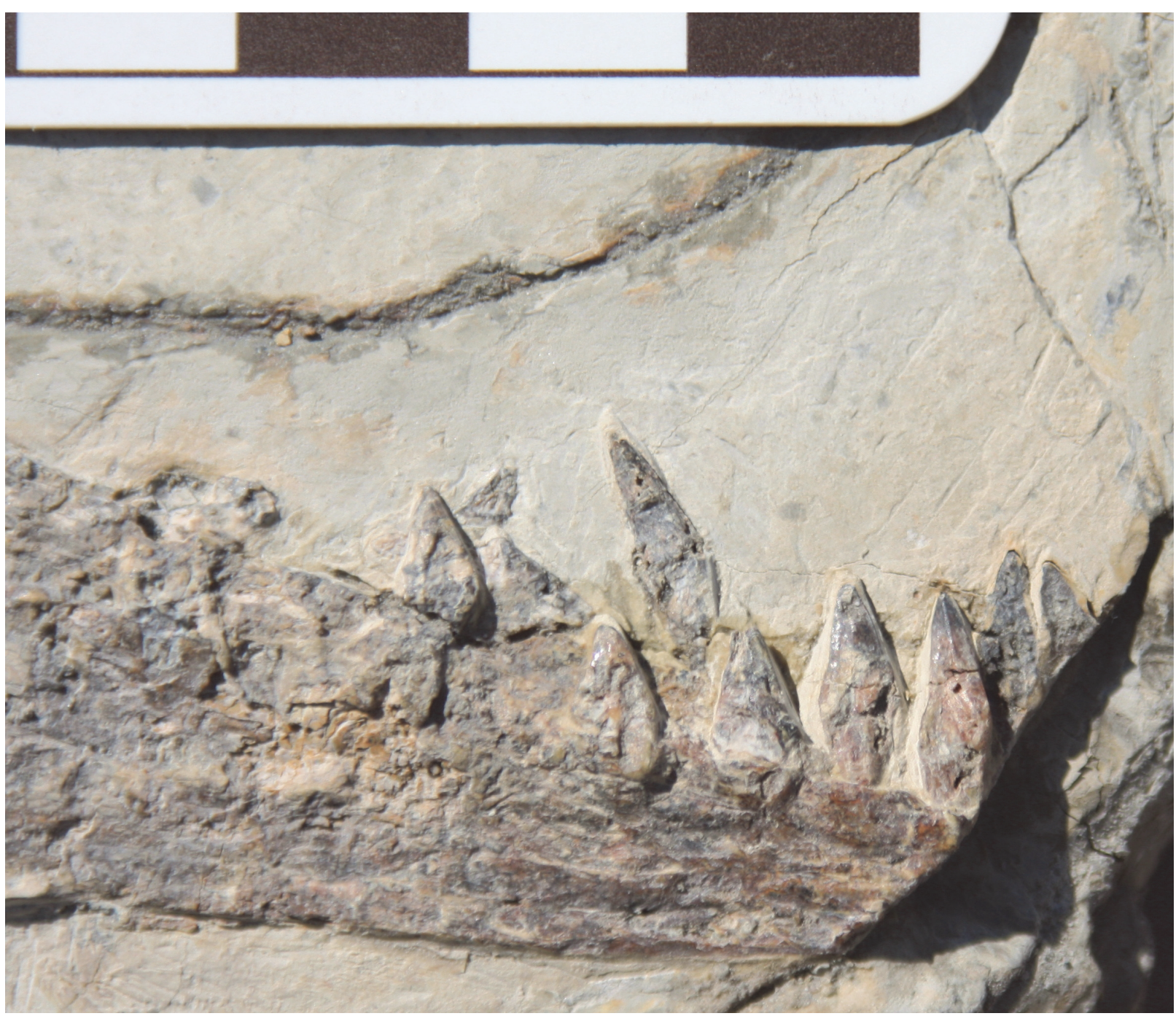

FIGURE S1. Close up of the premaxillary teeth of ELDM 1000 in lateral view. Scale bar has $1 \mathrm{~cm}$ divisions. 


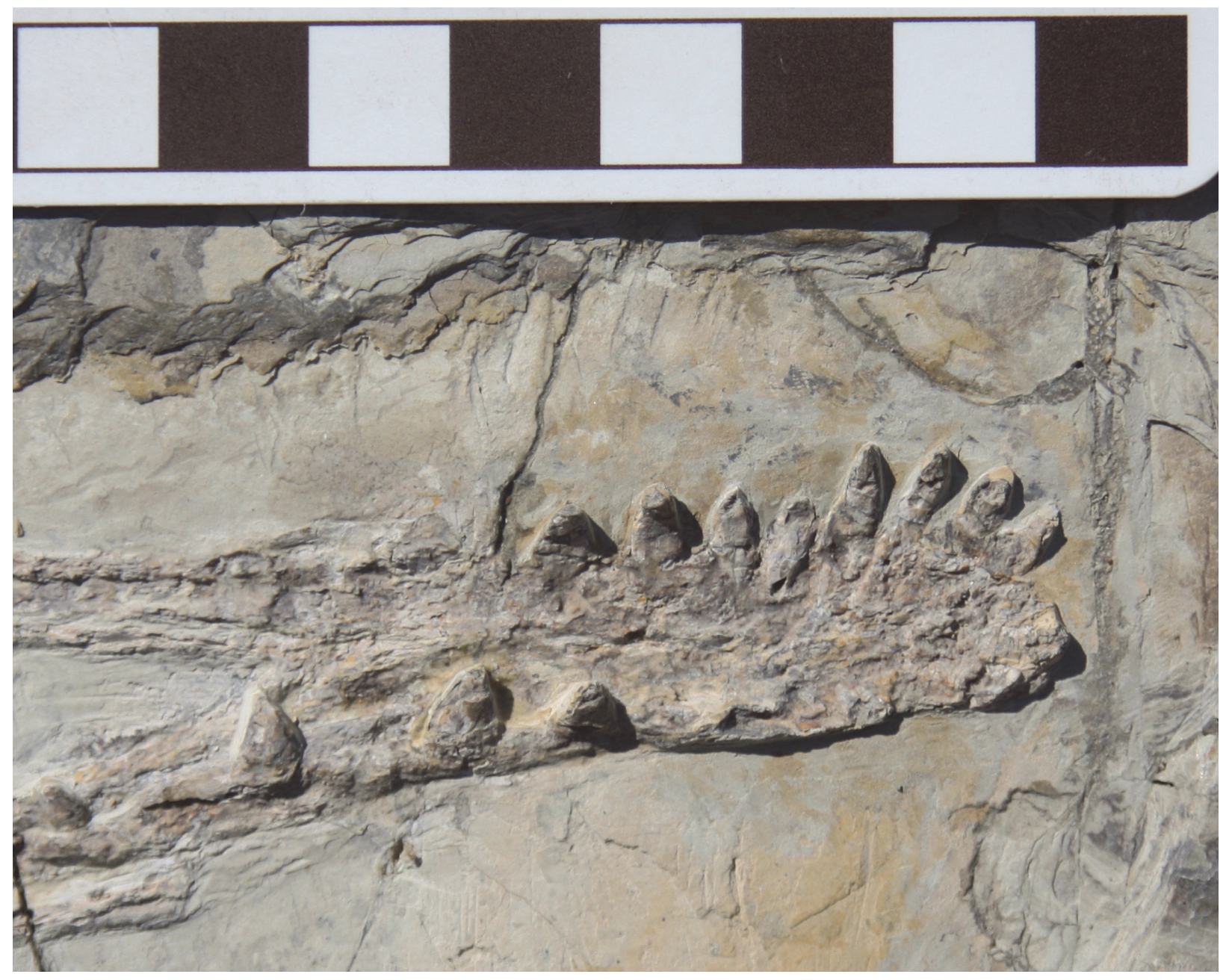

FIGURE S2. Close up of the mandibular teeth and symphysis of ELDM 1000 in dorsal view. Scale bar has $1 \mathrm{~cm}$ divisions. 


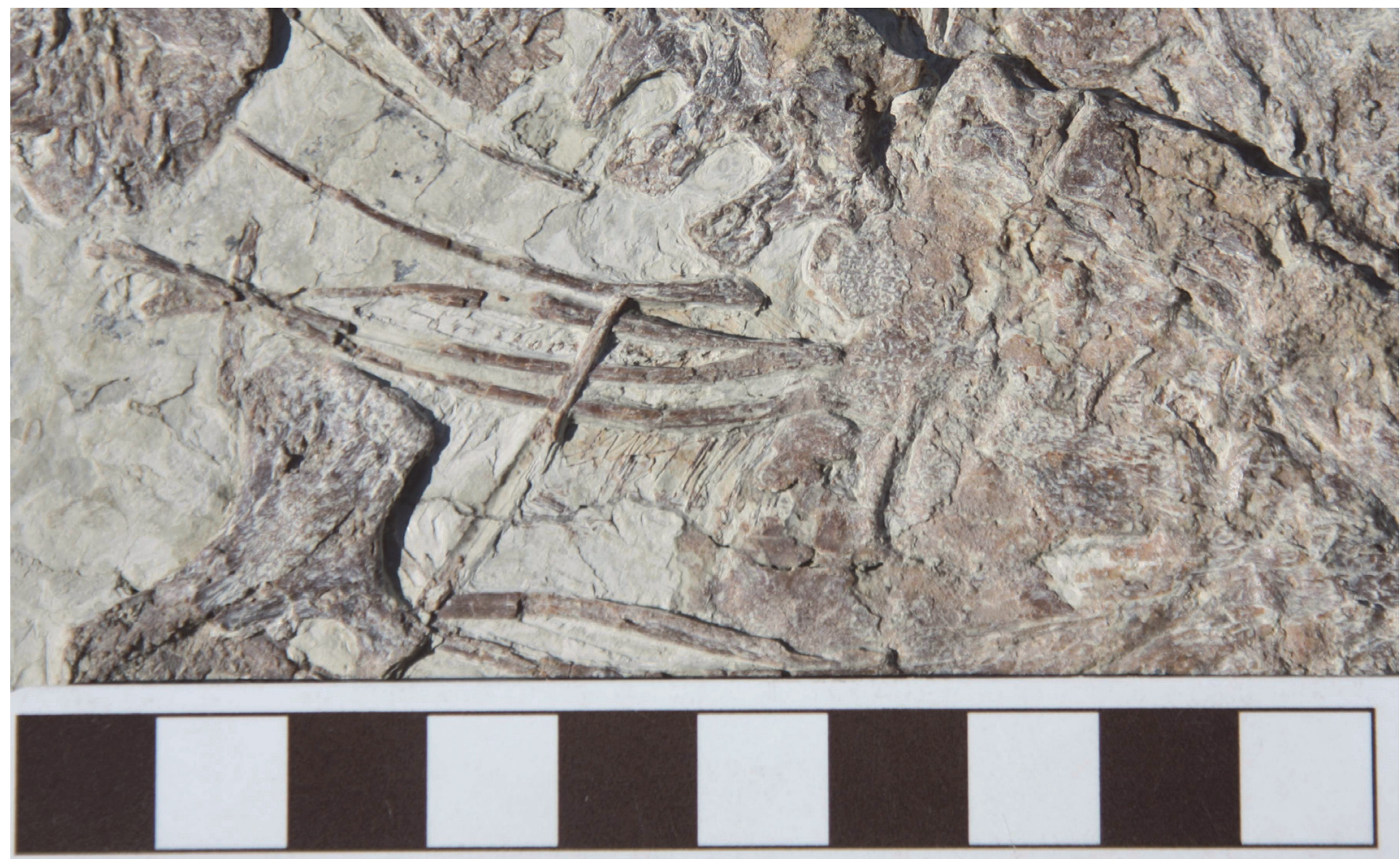

FIGURE S3. Close up of the fish preserved under the dorsal ribs of ELDM 1000. Scale bar has 1 $\mathrm{cm}$ divisions. 


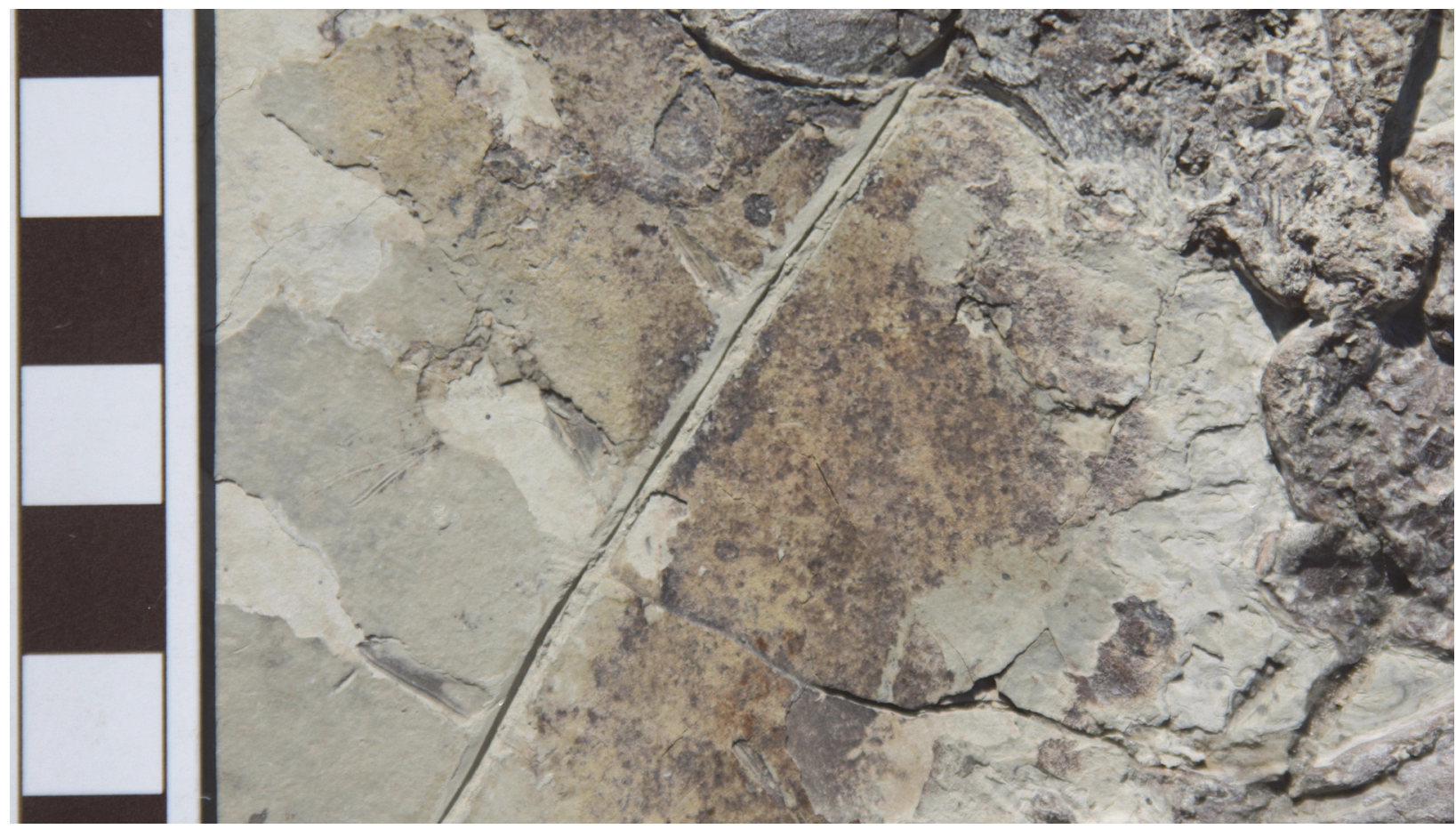

FIGURE S4. Close up of part of the large patch of probable skin on ELDM 1000. Scale bar has $1 \mathrm{~cm}$ divisions.

\section{PE Note: Corrigendum to Hone et al. (2020)} 19 May 2020

\section{Corrigendum to}

Hone, D.W.E., Fitch, A.J., Ma, F., and Xu, X. 2020. An unusual new genus of istiodactylid pterosaur from China based on a near complete specimen. Palaeontologia Electronica, 23(1):a09. https://doi.org/10.26879/1015

palaeo-electronica.org/content/2020/2931-a-new-istiodactylid-pterosaur

In the published paper, the species name Luchibang xingzhe was given in the abstract and used elsewhere in the paper, but the species name was given as 'xinzhe' in the Systematic Palaeontology section. The former was the intention of the authors and the alternate use in error. According to section 32.5 of the ICZN this should be corrected, and we formally change this to Luchibang xingzhe.

Similarly, our original planned species name for this taxon 'wuke' appears in Figure 8 and the supplementary files. Since this name does not have a description, under Article 13 of the ICZN this is therefore a nomen nudum and should not be considered valid. 